\title{
Effect Of n-Amyl Alcohol/Biodiesel Blended Nano Additives on the Performance, Combustion and Emission Characteristics of CRDI Diesel Engine
}

Prabhu Kishore Nutakki

National Institute of Technology Andhra Pradesh

Santhosh Kumar Gugulothu ( $\square$ santoshgk1988@gmail.com )

National Institute of Technology Andhra Pradesh

Jatoth Ramachander

National Institute of Technology Andhra Pradesh

Mulugundam Sivasurya

GITAM Institute of Technology

\section{Research Article}

Keywords: Iron oxide, additives, ternary fuel, trade-off, Performance, combustion and emissions

Posted Date: February 11th, 2021

DOl: https://doi.org/10.21203/rs.3.rs-223789/v2

License: (9) This work is licensed under a Creative Commons Attribution 4.0 International License.

Read Full License

Version of Record: A version of this preprint was published at Environmental Science and Pollution Research on March 6th, 2021. See the published version at https://doi.org/10.1007/s11356-021-13165-5. 


\section{Abstract}

This paper deals with the study on the influence of the effects of iron oxide nanoparticle additives when added to ternary fuel (diesel + Mahua methyl ester + Pentanol) on the emission, combustion and performance characteristics of a four stroke, single cylinder, common rail direct injection diesel engine working at a constant speed and varying operating scenarios. Doping is done in various proportions to the nanoparticle additives with the help of a homogenizer and ultrasonicator where the cationic surfactant used is CTAB (cetyl trimethyl ammonium bromide). Iron oxide nanoparticles were used as additives in fuel in the dosages of $40 \mathrm{ppm}, 80 \mathrm{ppm} \& 120 \mathrm{ppm}$ respectively and TF (Ternary fuel) is obtained by mixing $10 \%$ pentanol, $20 \%$ Mahua and $70 \%$ diesel together is used for the experimental study. The experimental study revealed that while using the nanoparticle additives blended ternary fuel (i.e., TF80) the number of harmful pollutants like smoke (5.38\%), HC (6.39\%), carbon monoxide (10.24\%) and $\mathrm{NO}_{\mathrm{x}}$ etc. has reduced to a considerable extent and there was a commendable improvement in the BTE by $8.8 \%$. So, we can summarize that when ternary fuel and nano additives are blended together the combustion and performance of the engine was improved considerably and pollutant emissions were decreased.

\section{Introduction}

Ternary fuel blends have become very popular recently around the world due to its ability to use as a substitute for conventional diesel. (Rakopous et al. 2008) investigated the influence of alcohol with different concentrations (10\% and $5 \%$ ) along with diesel fuel. There was a significant improvement in the performance of the engine and the emission characteristics while using $10 \%$ ethanol-diesel blend when compared with the $5 \%$ blend of same. Selvan et al. (2009) studied about the effect of CO (cerium oxide) nano additive concentration in ethanol- biodiesel-diesel blends and results revealed that there was an increase in fuel consumption whereas brake thermal efficiency reduced when compared to conventional diesel fuel. (Barabas et al. 2010) investigated on multi cylinder $\mathrm{Cl}$ with bio-ethanol/biodiesel/diesel and studied about the emissions and performance characteristics and reported that at part loads, the reduction in performance because of less heating value. Carbon monoxide and hydrocarbons emissions were reduced while using biodiesel-diesel-ethanol blend. Fang et al (2013) and Qi et al (2011) also submitted alike reports regarding the usage of biodiesel- ethanol- pure diesel blend in diesel engines. Nitrogen oxide emissions were considerably decreased when the ternary blend was used in comparison with pure diesel for entire load conditions. Hulwan et al. (2011) studied about the practicality of ethanol in high concentrations in the diesel-ethanol blends and reported that the nitrogen oxide emissions were increased considerably. However, carbon monoxide emissions increased at smaller loads and smoke opacity reduced for higher loads. (Fang et al. 2013) investigated the effect of characteristics of biodiesel blends on combustion and emission characteristics of diesel engine and reported that ethanol-dieselbiodiesel blends have lower NOx emissions due to lower combustion temperature, resulting from the higher latent heat of vaporization. An improved model of ethanol- biodiesel- diesel fuel blend was formulated by Lin et al. (2013). They conducted experiments with different fuel blends which can improve 
the entire profitability of the system, with given the cost of production, prices of fuels etc. Datta and Mandal (2014) studied about the suitability and ANPs at varying concentrations of $100,75,50,25 \mathrm{mg} / \mathrm{I}$ with DBF (diestrol blended fuel)- $70 \%$ diesel $+20 \%$ ethanol $+10 \%$ jojoba biodiesel on the utilization of engine characteristics and reported that at a dosage of $25 \mathrm{mg} / \mathrm{I}$ the hydrocarbons and nitrogen oxide emission decreased in comparison with other nanoparticles additives. Sandalc et al. (2014) examined the impact of ethanol on diesel engine under two operating conditions i.e., $30 \%$ and $15 \%$ diesel fuel levels (on the basis of volume). No separation of phase was observed and the blend of ethanol and diesel was very stable throughout the operation. They also witnessed a considerable decrease in smoke and nitrogen oxide emissions in comparison with diesel fuel. Yilmaz et al. (2014) analyzed the impact of ternary blend and reported that changing ethanol concentrations resulted in varying emission characteristics due to varying oxygen content and cooling effect of ethanol. They concluded that the ethanol concentration in the blend decreased the carbon monoxide and hydrocarbon emissions and increased the nitrogen oxide emissions. Li et al. (2014) investigated the influence of ternary blend in a diesel engine of $1600 \mathrm{rpm}$ speed (constant) and reported that the addition of pentanol resulting in the betterment of air- fuel mixing rate, greater thermal efficiency and lesser emissions. (Shaafi et al. 2015) investigated about the impact of ANP at dosage of $100 \mathrm{mg} / \mathrm{l}$ in both ternary blend of $1 \%$ surfactant $+4 \%$ ethanol $+15 \%$ soybean diesel + $80 \%$ diesel and binary blends - B2 and reported that the heat release rate and cylinder pressure of ternary blend displayed higher value, due to high value of the surface area to volume ratio of alumina. Venu et al. (2016) studied about the impact of ANP in ethanol - biodiesel-diesel ternary blend at different injection timings and found that the combustion of nanoparticles was effectual in delayed injection timing and decreasing the hazardous tailpipe emissions like nitrogen oxide, carbon monoxide, smoke and hydrocarbons. (Prabu et al. 2016; Gugulothu et al.2016) investigated the influence of nano additives blended with jatropha in a diesel engine and reported that the high brake thermal efficiency of $31 \%$ and a decreased value of brake specific fuel consumption of $0.293 \mathrm{~kg} / \mathrm{kWh}$.

(Venu et al. 2017) through his studies found that addition of nanoparticles into ternary fuel blend is much better than the addition of oxygenated additives. Hosseini et al. (2017) studied about the impact of ANPs as catalysts in blends of $95 \%$ diesel \& $5 \%$ WCO biodiesel (B5 Blend) and $90 \%$ diesel $+10 \%$ WCO biodiesel blend (B10 blend) in a diesel engine and reported that B10AL90(90 ppm ANP in B10 blend) shows higher brake thermal efficiency, power, EGT and torque of values of $10.63 \%, 5.36 \%, 5.8 \%$ and $5.36 \%$ respectively when compared to conventional diesel fuel, while brake specific fuel consumption decreased to $14.66 \%$. Chokalingam et al (2017) investigated on diesel engine by adding $10 \%$ ethanol to diesel and it was observed that the performance was similar to that of diesel fuel. (Nour et al.2018) studied about the ANP (Alumina nanoparticles) at different concentrations of 100, 75, 50 and $25 \mathrm{mg} / \mathrm{l}$ mixed into a DEB (Diestrol blended- $70 \%$ diesel $+20 \%$ ethanol $+10 \%$ jojoba diesel) fuel and their effect on various diesel engine characteristics. When $25 \mathrm{mg} /$ I dosage of ANP was used there was a decrease in hydrocarbons and nitrogen oxides emissions when compared with other nanoparticles addition. (Wu et al. 2018) investigated the influence of nanoparticle additives used as fuel catalyst in the blend of diesel- biodiesel, to study the performance characteristics of the engine and reported that BSFC reduced by $6 \%$, emissions of $\mathrm{HC}$ decreased by $14.5 \%$ and $\mathrm{CO}$ reduced by $10 \%$ when compared with the biodiesel blend of $10 \%$. 
(Sivakumar et al. 2018) studied about the impact of ANPs for a fuel blend of 75\% diesel-25\% pongamia biodiesel inside a diesel engine(single-cylinder) and reported that the B25 blend with $100 \mathrm{ppm}$ alumina doping resulted in a reduction of brake specific fuel consumption by $16.67 \%$ and increased brake thermal efficiency to $8.36 \%$ when compared to normal B25 blend without alumina doping. (Charoensaegn et al. 2018) conducted an experiment in a diesel engine with palm biodiesel-diesel-ethanol blend as fuel, and studied about emissions from the engine tailpipe and revealed that the microemulsion biofuels presented an increase in SFC and reduction in nitrogen oxide emissions to an extent. (Soudagar et al. 2018; Gugulothu et al.2019) investigated the impact of nanoparticles on performance characteristics of biodiesel blended diesel engine and reported that incorporation of nano additives resulted in an increase in improvement of thermophysical properties, decrease in emissions from engine tailpipe, better stabilization of air-fuel mixture. (El-Seessy et al.2018) studied the impact of nanoparticle additives blended biodiesel to study the performance characteristics of diesel engine on various loading conditions by adding different ANPs (aluminium oxide nanoparticles) concentrations and reported that at full load condition, there was a decrease in various exhaust emissions like hydrocarbons reduced by $80 \%$, nitrogen oxides by $70 \%$ and carbon monoxide reduced by $60 \%$. Ghadikolaei et al. (2019) studied the formation of particulate matter and chemical properties of ternary fuel blend of ethanol-biodiesel-diesel, at various load conditions. They found out that this type of blend has a better impact on DPFE (diesel particulate filter efficiency) and the obtained value of metal elements was $0.7 \%$ and ions $1.9 \%$ and diesel particulate matter was $85.8 \%$.

Aydin and Yesilyurt (2020) studied the performance characteristics while using the DEE (diethyl ether) and cottonseed oil blend in the diesel engine at various load conditions. Diethyl ether was added to $20 \%$ biodiesel- cottonseed blend at various concentrations like $10 \%, 7.5 \%, 5 \%$, and $2.5 \%$ (on the basis of volume). While adding $10 \%$ Diethyl ether to $20 \%$ cottonseed- biodiesel blend, it was observed that thermal efficiency was decreased by $17.39 \%$ and Brake specific fuel consumption shown an increase of $29.15 \%$. Dogan et al (2020) studied about the diesel engine characteristics which incorporates alcohol as an oxygenated fuel by considering various parameters like sustainability, enviro-economic, exergoeconomic, exergy and energy were analyzed and reported that 20\% 10\% and 5\% 1-heptanol was added (on the basis of volume) to the pure diesel and test results show that SFC is more for $20 \% 1$ - heptanol blend of 0 . $221 \mathrm{~kg} . \mathrm{kWh}$. (Yesilyurt et al.2020) studied the impact of ternary blends of safflower-diesel on the various characteristics of a diesel engine. Through the studies, they concluded that brake specific fuel consumption shows a decrease and brake thermal efficiency shows an increase when ternary fuel blend was used. Addition of pentanol also reduced the emissions of smoke, hydrocarbons and carbon monoxide. Yesilyurt (2020) conducted various tests on diesel engine with a tri-fuel blend of dieselbiodiesel-cooking oil, at various fuel injection pressures of (220 bar, 210 bar, 190 bar, 180 bars, and 170 bar) and reported that BTE has increased considerably at higher injection pressure. Yesilyurt et al. (2020) studied about the blend of four fuels i.e., vegetable oil-alcohol-biodiesel- diesel blend, to analyze the emission, combustion and performance characteristics of a diesel engine. From the results obtained, the author recommends using a 4-fuel blend to achieve better performance in diesel engine in the future. Yesilyurt and Arslan (2019) investigated to study the influence of injection parameters on diesel engine 
and reported that while using diesel fuel at 190 bar it was found that a maximum of exergy and energy efficiency of $21.27 \%$ and $24.5 \%$ was obtained. Vinod Babu et al. (2020) investigated the influence of multiple injections and start of injection parameters by implementing a response surface methodology approach on diesel engines and reported that with $61.1 \mathrm{MPa}$ injection pressure, minimal emission characteristics are obtained. Ashok et al. (2020) investigated the influence of lemon peel oil on the performance and emission characteristics by implementing a response surface methodology technique on diesel engines and reported that the superior passenger comfort lemon peel oil blend is companionable to reduce the appropriate damping effects. Kumar et al. (2019) investigated the effect of the hybrid entropy-VIKOR approach on the non-road diesel engine to optimize the operating parameters and reported that optimum performance parameters are attained at an injection timing of $360 \mathrm{crank}$ angle degree and a fuel injection pressure of 210 bar. By simplifying appropriate algorithms, an artificial neural network is a suitable model in the machine learning approach that delivers proper outcomes (Bhowmik et al.2017 and Bhowmik et al.2018). Kapoor et al. (2020) investigated the influence of nanoparticle-blended biofuel on the performance and emission characteristics by implementing the BoxBehnken design methodology technique on diesel engines and reported that nanoparticles mixed blends enhance the performance characteristics and reduce the harmful emissions.

According to ASTM standards, the chemical and physical characteristics of this ternary fuel is very close to that of conventional diesel fuel (Gugulothu et al.2021). But there was a lack of a decent number of technical literatures on the emission, combustion and performance characteristics of ternary fuel blends for application in a diesel engine. A limited number of studies focused on finding the best mixing concentration of nano additives with base fuel, which can provide better performance of the engine and fewer exhaust emissions. The fuel characteristics of nano additives blended ternary fuel is superior so we can utilize the usage of viable energy resources like biodiesel and bioethanol to its full extent by adding the nano additives. By this way, we can satisfy the emerging demand for fossil fuels in the present scenario. From this study, a sincere effort has been made to understand the major impacts of MME20 (80\% diesel fuel $+20 \%$ Mahua methyl ester), Ternary fuel (pentanol $10 \%+$ MME20\%+ diesel $70 \%$ ), Ternary fuel 40 (Ternary fuel mixed with iron oxide additives of $40 \mathrm{ppm}$ ), Ternary fuel 80 (Ternary fuel mixed with 80 ppm iron oxide additives) and Ternary fuel 120(Ternary fuel mixed with iron oxide additives of 120 $\mathrm{ppm}$ ) blends on exhaust emissions, combustion and engine performance in a four stroke, single cylinder, common rail direct injection diesel engine (with similar operating conditions) and the obtained results are compared with that of conventional diesel conventional diesel (D100).

\section{Materials And Methodology}

\section{Mahua Methyl Ester Preparation}

Figure 1 represents the diagram of a biodiesel plant obtained from approved technologies that can be used for making methyl ester. Vegetable oil can be tailored in such a way to decrease its density and viscosity, so that the final product produced will have adequate properties to be used as a diesel engine fuel (Singh.P et al.2016). The process of using an alcohol to break down the molecules of untreated 
vegetable oil into methyl in the presence of a catalyst $(\mathrm{KOH}$ or $\mathrm{NaOH})$ is known as transesterification. This process produces glycerin as a by-product which can be used for other purposes. For this process, the catalyst used is $\mathrm{KOH}$ at a concentration of $7 \mathrm{~g} /$ litre dissolved with methanol though powerful stirrings inside a reactor (Singh et al.2017). Next step involves the mixing of the catalyst-methanol mixture with crude mahua oil. Finally, the vigorous stirring of the final mixture for 60 minutes at $60^{\circ} \mathrm{C}$ in ambient pressure. After the completion of a transesterification process, two different liquid phases are formed i.e., glycerin and methyl ester. Being in the heavier side, liquid raw glycerin will sink into the bottom after few hours of settling process. After settling, phase separation gets completed in 2-3 hours. Whereas complete settling of methyl ester can take up to 8-10 hours. Methyl ester washing requires two steps. A wash solution made with $1 \mathrm{gm}$ tannic acid per litre of water and vegetable oil (26\%) and is mixed to the methyl ester and then emulsified. Stirring is maintained until the methyl ester becomes transparent. The viscosity values of both methyl esters were found to be decreased after the transesterification process, and the value is closer to that of diesel fuel. Methyl ester made through above mentioned process $20 \%$ is then blended with plain diesel $80 \%$ for preparation of biodiesel blends that can be used in CRDI engine for performing various tests.

\section{Preparation of Ternary fuel blend}

As mentioned in the introduction, a TF blend was put forward with $70 \%$ diesel, $20 \% \mathrm{MME}$ and $10 \%$ pentanol. Magnetic stirring is done for two hours for 1 liter of this mixture. The obtained blend is named as TF and various tests were conducted according to ASTM standards for deciding various properties like the flashpoint, cetane number, calorific value, kinematic viscosity and density and values are given in Table 1. Cetane number, viscosity and density was decreased by $8.16 \%, 26.73 \%$ and $2.52 \%$ respectively, when compared to $100 \%$ MME fuel and higher than diesel fuel by $0.83 \%, 11.97 \%$ and $1.43 \%$ respectively. Still the properties of TF blend are not a match to conventional diesel fuel. To overcome this iron oxide additives into the ternary fuel at 3 proportions of 40,80 , and $120 \mathrm{ppm}$ and then studied about the properties again and done various tests with this iron oxide nano additives doped TF blends, along with base fuel.

Table 1. Properties of diesel and ternary fuel blende nano additives (Ramachander et al.2021) 


\begin{tabular}{|lllllll|}
\hline Properties & Fuels & \multicolumn{5}{l|}{} \\
\cline { 2 - 7 } & $\begin{array}{l}\text { Density at } \\
20^{\circ} \mathrm{C}\left(\mathrm{kg} / \mathrm{m}^{3}\right)\end{array}$ & $\begin{array}{l}\text { Viscosity at } \\
40^{0} \mathrm{C}(\mathrm{cSt})\end{array}$ & $\begin{array}{l}\text { Cetane } \\
\text { number }\end{array}$ & $\begin{array}{l}\text { Calorific } \\
\text { value }(\mathrm{kJ} / \mathrm{kg})\end{array}$ & $\begin{array}{l}\text { Fire } \\
\text { point }\left({ }^{0} \mathrm{C}\right)\end{array}$ & $\begin{array}{l}\text { Flash } \\
\text { point } \\
\left({ }^{0} \mathrm{C}\right)\end{array}$ \\
\hline D100 & 830 & 4.1 & 45 & 42000 & 53 & 3.5 \\
\hline MME20 & 858 & 4.7 & 53 & 41950 & 132 & 2 \\
\hline TF & 841 & 3.3 & 48 & 41620 & 73 & 3 \\
\hline TF40 & 839 & 3.37 & 48.5 & 41728 & 69 & 2.8 \\
\hline TF80 & 837 & 3.21 & 55 & 41963 & 66 & 4 \\
\hline TF120 & 830 & 3.01 & 47.4 & 42965 & 65 & 3 \\
\hline $\begin{array}{l}\text { ASTM } \\
\text { standards }\end{array}$ & D1298 & D445 & D976 & D240 & D92 & D93 \\
\hline
\end{tabular}

\section{Preparation of Ternary Fuel Blended Nano Additives}

$\mathrm{Fe}_{2} \mathrm{O}_{3}$ nanoparticles of size ranging from $32 \mathrm{~nm}$ to $48 \mathrm{~nm}$ was suspended in the base fuel (MME20). $\mathrm{Fe}_{2} \mathrm{O}_{3}$ nanoparticles dose levels were calculated by its mass in the base fuel ranging from 40 to $120 \mathrm{ppm}$ by using a precision electronic balance. $\mathrm{Fe}_{2} \mathrm{O}_{3}$ nanoparticles are dispersed into MME20 base fuel in different concentrations of 40,80 and $120 \mathrm{ppm}$ with the help of a ultrasonicator. An ultrasonicator of 250 W was adjusted at $45 \mathrm{kHz}$ frequency to produce a consistent mixture of Mahua methyl ester blend and nanoparticles was performed for 30-45 minutes of agitation with $350 \mathrm{rpm}$ at $70^{\circ} \mathrm{C}$ temperature.

The density of biodiesel blended nanoparticles increased due to the increase in concentration of nanoparticles in test fuel. Similarly, the flash and fire point of the $\mathrm{Fe}_{2} \mathrm{O}_{3}$ nanoparticle blended biodiesel were found lesser than MME20, due to the greater oxygen content. TF blend is made by mixing $10 \%$ pentanol (v/v), 20\% biodiesel (v/v) and 70\% diesel ( $\mathrm{v} / \mathrm{v})$ and then mixed magnetically stirred for two hours. Iron oxide nano additives are blended into TF blend at different concentrations of 40,80 and 120 ppm and the blends are named as TF40, TF80 and TF120 respectively. Nano additives are blended by the ultrasonication method as this method facilitates uniform dispersion of the nanoparticles into the base fuel (Surya et al.2021; Kumar et al.2020). Table 1 represents the iron oxide blended ternary fuel properties and it is observed that as the concentration of nanoparticles increase in the ternary fuel blend, cetane number, kinematic viscosity and density decreases. Ternary fuel blended with $40 \mathrm{ppm}$ iron oxide nano additives has a high cetane number of 48.5 , reduced kinematic viscosity of $3.37 \mathrm{~mm}^{2} / \mathrm{s}$, high calorific value of $43846 \mathrm{~kJ} / \mathrm{kg}$. So, from the detailed analysis of fuel properties, we can summarize that the best doping value is $80 \mathrm{ppm}$ for the ternary fuel blend, for improvised fuel characteristics. When the doping level was decreased to $40 \mathrm{ppm}$ and increased to $120 \mathrm{ppm}$, no particular change was witnessed in the physical properties of iron oxide nano additives blended ternary fuel. Each iron oxide nano additives 
blended TF samples of different concentrations is placed in a tube made of glass for 15 hours (under static conditions) for stability investigation purpose (Gugulothu et al.2020).

\section{Experimental Set-up and Methodology}

A 4S (4 stroke), Single cylinder, Kirloskar AV1 diesel engine was used to perform the experiments, which was assisted by CRDI system. The power of the diesel engine was rated as $3.7 \mathrm{~kW}$. The injection pressure was kept at the range of 245-500 bar and speed of the engine was $1500 \mathrm{rpm}$ with different load scenarios. During the initial stage, in order to obtain the baseline data conventional diesel was used in the engine, then MME20 (80\% diesel fuel + 20\% Mahua methyl ester), Ternary fuel (pentanol 10\%+ MME20\%+ diesel 70\%), Ternary fuel 40 (Ternary fuel mixed with iron oxide additives of $40 \mathrm{ppm}$ ), Ternary fuel 80 (Ternary fuel mixed with 80 ppm iron oxide additives) and Ternary fuel 120(Ternary fuel mixed with iron oxide additives of $120 \mathrm{ppm}$ were used. Table 2 describes the specifications of the engine. Figure 2 represents the schematic of the experimental setup. A gas analyser (Model DiGas 444 5, AVL India Pvt, Ltd.) conforming to ARAl certification-ARAI/TA (4G-RV)/AVL/DiGas 444/0910-12) was used to measure the emissions of $\mathrm{CO}, \mathrm{CO}_{2}$, and $\mathrm{O}_{2}$, in terms of volume percentage, while hydrocarbon emissions were measured in ppm (vol.) of n-hexane equivalent and $\mathrm{NOx}$ emissions were measured in ppm (vol.). $\mathrm{CO}, \mathrm{CO}_{2}$, and hydrocarbon emissions were measured based on the principle of nondispersive-infrared (NDIR) detection, while $\mathrm{NOx}$ and $\mathrm{O}_{2}$ were measured by means of pre-calibrated electrochemical sensors. The opacity of the exhaust smoke was measured by means of a Model AVL 437 opacimeter (AVL India Pvt, Ltd.). The opacimeter had a measuring chamber of defined measuring length and nonreflecting surface, which was filled homogeneously with exhaust gas. The loss of light intensity between a light source and a receiver was measured and, from it, the opacity of the exhaust gas was calculated. The calculation was based on the Beer-Lambert law. The analyzers were interfaced through their respective RS $232 \mathrm{C}$ serial communication bus to an emission data acquisition platform that recorded the emission data for $120 \mathrm{~s}$ in intervals of $20 \mathrm{~s}$.

According to the first law of thermodynamics,

$$
\begin{gathered}
\frac{d U}{d t}=Q-W \\
m C_{v} \frac{d T}{d t}=Q-P \frac{d V}{d t}
\end{gathered}
$$

where, $\mathrm{Q}$ is the combination of the heat release rate and heat transfer rate across the cylinder wall, $\mathrm{W}$ is the rate of work done by the system due to system boundary displacement. To simplify Eq. (2), the ideal gas assumption can be used

$$
P V=m R T
$$


Assuming constant mass, Eq. (3) is differentiated as:

$$
\frac{d T}{d t}=\frac{1}{m R}\left[P \frac{d V}{d t}+V \frac{d P}{d t}\right]
$$

After combining these two equations, the heat release equation becomes

$$
Q=\left[\frac{C_{v}}{R}+1\right] P \frac{d V}{d t}+\frac{C_{v}}{R} V \frac{d P}{d t}
$$

After replacing time $(t)$ with the crank angle $(\theta)$, Eq. (5) becomes

$$
Q_{t}=\frac{k}{k-1} P \frac{\partial V}{\partial \theta}+\frac{1}{1-k} V \frac{\partial P}{\partial \theta}
$$

where, $\mathrm{k}$ is the ratio of specific heats and taken as 1.35 for diesel heat release analysis, $\theta$ is the crank angle, $\mathrm{P}$ is the cylinder gas pressure, and $\mathrm{V}$ is the cylinder volume.

BSFC was calculated in order to evaluate the engine performance depending on the fuel types used in the study. For this purpose, Eqs. (2) and (3) were used to achieve the BSFC data [43].

$$
\begin{array}{r}
B P=\frac{2 \pi \omega T}{1000} \\
B S F C=\frac{m_{f} \times 10^{6}}{B P}
\end{array}
$$

Eq. (4) was also used to determine BTE values (\%) in the present paper. BTE represents the brake thermal efficiency and LHV $(\mathrm{MJ} / \mathrm{kg})$ represents the lower heating value of the used fuel.

$$
B T E=\frac{3600}{B S F C \times L H V} \times 100
$$

Table 2. Details of experimental test rig 


\begin{tabular}{|ll|}
\hline Make and type & Kirloskar 3.7 kW vertical CRDI engine \\
\hline Engine type & Automotive (Multispeed) \\
\hline Stroke length & 110 millimeter \\
\hline Swept volume & 625 cubic centimeters \\
\hline Compression ratio & $18.0: 1$ \\
\hline Torque/Power & 30 Nm@2000 RPM, 9 bhp@3000 RPM \\
\hline Injectors & Solenoid \\
Fuel Injection & Common rail direct injection system \\
\hline Dynamometer & \\
\hline Make & Power Mag \\
\hline Type & Eddy current \\
\hline Load measurement method & Strain Gauge \\
\hline Maximum load & 12-kilogram \\
\hline Cooling & Water \\
\hline
\end{tabular}

Table 3. Instruments used for Measurement 


\begin{tabular}{|c|c|c|c|c|}
\hline Instruments used with model & $\begin{array}{l}\text { Measuring } \\
\text { parameter }\end{array}$ & Measuring range & Accuracy & Errors \\
\hline $\begin{array}{l}\text { TMEC10 Technomech Eddy Current } \\
\text { Dynamometer }\end{array}$ & Torque & $\begin{array}{l}10 \text { BHP @ } 1500 \text { - } \\
5000 \text { rpm }\end{array}$ & \pm 0.25 & \pm 0.2 \\
\hline EUREKA model PG5 & Air flow & $25-250$ Iph & \pm 1 & \pm 1 \\
\hline \multicolumn{5}{|l|}{ Rotameter } \\
\hline KISTLER Pressure Sensor & Pressure & 0 - 200 bar & \pm 0.75 & \pm 0.1 \\
\hline AVL 437 smoke-meter & Smoke & $0-100 \%$ & \pm 1 & $\pm 1 \%$ \\
\hline \multirow[t]{5}{*}{ AVL DI GAS 444N analyser } & NO & $0-2,000 \mathrm{ppm}$ & \pm 5 & $\stackrel{ \pm}{0.25}$ \\
\hline & $\mathrm{HC}$ & $0-20,000$ ppm & \pm 3 & \pm 0.3 \\
\hline & $\mathrm{CO}$ & $0-15 \%$ vol & \pm 0.013 & $\stackrel{ \pm}{0.13}$ \\
\hline & $\mathrm{O}_{2}$ & $0-25 \%$ vol & \pm 0.025 & 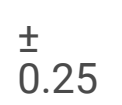 \\
\hline & $\mathrm{CO}_{2}$ & $0-20 \% \mathrm{vol}$ & \pm 0.15 & \pm 0.2 \\
\hline
\end{tabular}

\section{Uncertainty Analysis}

Precise calibration with optimal atmospheric conditions is equally important while using precision measurement devices for reliability. uncertainty analysis gives a broad view of experimental repeatability by counting necessary errors during measurement. In given atmospheric conditions, the process of quantifying performance and emission parameter measurement errors due to the methodology of the experiment, observation accuracy, calibration and instrumentation employed is called the experimental uncertainty analysis. Two major components are identified with uncertainty analysis one of which is repeated measurement random variation and second is accuracy bias. The equation (10) shows the total uncertainty as below.

\section{Overall uncertainty of the experiment $=$} $\sqrt{(B P)^{2}+(F C)^{2}+(B S F C)^{2}+(B T E)^{2}+(H C)^{2}+(C O)^{2}}+(N O)^{2}+(\text { Load })^{2}+$ (Pressure transducer $)^{2}+(\text { smoke })^{2}$

$$
\begin{gathered}
\sqrt{(1.11)^{2}+(0.66)^{2}+(1.29)^{2}+(1.29)^{2}+(0.2)^{2}+(0.2)^{2}+}(0.46)^{2}+(0.1)^{2}+(1.2)^{2} \\
= \pm 2.595 \%
\end{gathered}
$$

The evaluation of uncertainty values of each equipment was conducted, which established the experimental uncertainty (current) to be $\pm 2 \%$. This value is obviously within the acceptable uncertainty 
range i.e., less than $\pm 5 \%$.

\section{Results And Discussion}

The working of diesel engine aided by common rail direct injection system with fuel as MME20 (80\% diesel fuel + 20\% Mahua methyl ester), Ternary fuel (pentanol $10 \%+$ MME20\%+ diesel $70 \%$ ), Ternary fuel 40 (Ternary fuel mixed with iron oxide additives of $40 \mathrm{ppm}$ ), Ternary fuel 80 (Ternary fuel mixed with 80 ppm iron oxide additives) and Ternary fuel 120(Ternary fuel mixed with iron oxide additives of $120 \mathrm{ppm}$ ) blends and was observed to be pretty clean for the entire rated load and no difficulties were faced. BSFC, BTE and emissions (nitrogen oxide emissions, $\mathrm{HC}, \mathrm{CO}$ ) and density of smoke are plotted against load. With the available data regarding combustion, HRR and cylinder pressure was plotted against crank angle.

\section{Engine Combustion characteristics}

In this section, heat release rate, in-cylinder pressure and ignition delay are discussed for all the fuels. These are the important parameters that help to understand the behavior of the fuel blends in the combustion chamber. Average temperature of the gas in the cylinder and the heat release rate is calculated using the "Enginesoft/LabView" software that uses the OD model of a single combustion zone with constant specific heat ratio.

\section{Cylinder Pressure}

Figure 3 illustrates the variation of inside cylinder pressure w.r.t to crank angle for all the test fuels. It is observed from the plot that MME20 at 53.42 bar pressure is the least point, whereas the highest point of cylinder pressure prevails for D100 at 55.45 bar. The fuel-air combination generation is fairly constant which results in increased pressure when the cetane number is improved and viscosity of fuel remains low. The air-fuel mixture becomes uniform and pressure gets increased due to lesser viscosity and better cetane number. Atomization and evaporation rate, the characteristics of air-fuel interaction with lower cylinder pressure are affected by higher density, viscosity, and lowered calorific value of MME20 as compared to D100 and this can be illustrated through Table 2. Cylinder pressure improved to 56.33 bar from 53.42 bar when ternary fuel blend was used instead of MME20 blend. Improved calorific value and lower viscosity are the main attributes. Pentanol's presence in ternary fuel helps the oxygen molecules present in it for effective combustion with improvement in cylinder-pressure. Cylinder pressure improves when ternary fuel is mixed with iron oxide nano additives as compared to TFB and MME20. For TF40 cylinder pressure was found at 55.99 bar, for TF80 it is 54.82 bar and for TF120, it is 57.11 bar. The reason for this increase in cylinder pressure is the higher surface area to volume ratio of iron oxide nano additives. This in turn improves the cylinder pressures along with efficient combustion and higher premixed combustion. When working with C.N.T. emulsified biodiesel in diesel engine, comparable trends were discovered by the scientists. Cylinder Pressure of TFB120 is found better, which is 57.11 bar measured amongst various concentrations and it is $2.33 \%$ greater from diesel. 


\section{Heat Release Rate}

Figure 4 illustrates the variation of heat release rate w.r.t to crank angle for all the test fuels at full load condition. When compared to other fuels, heat release rate of D100 is observed to be as $110.36 \mathrm{~J} / \mathrm{deg}-\mathrm{CA}$ this is due to the fact that the accumulation of diesel fuel at the primary combustion phase which is in the premixed stage. More heat also gets generated because of fuel 's lower cetane number as and when compared to other blends. Because of typical fuel properties, i.e., high density and viscosity due to which evaporation rate (premixed stage) is affected, the lowest heat release rate of $69.214 \mathrm{~J} /$ deg-CA gets exhibited for MME20. Diffusion combustion is prolonged as oxygen molecules present in it affects majorly at later stages of combustion. Also, MME20 liberates heat at prior crank angles completely before the Top dead Center (TDC) because of better cetane number properties. Heat release rate of ternary fuel blend (TFB) is observed to be $90.25 \mathrm{~J} / \mathrm{deg}$-CA which is almost $21.92 \%$ higher than that of MME20. The reason behind the hike could be pentanol's presence and lower relative amount of biodiesel, which when blended lowers down the fuel accumulation in the primary phase of combustion. TF40 exhibits heat release rate of $94.22 \mathrm{~J} / \mathrm{deg}-\mathrm{CA}$, for TF80 it is $96.22 \mathrm{~J} / \mathrm{deg}-\mathrm{CA}$ and for TF120, it is $98.66 \mathrm{~J} / \mathrm{deg}-\mathrm{CA}$ and it is higher than ternary fuel blend having HRR of $90.25 \mathrm{~J} /$ deg-CA. The cumulative heat release rate phenomenon represents a substantial variance in ID (ignition delay period) due to excess fuel deposition in premixed combustion. It also reflects a higher heat release rate and the lowest cumulative heat release rate. Thus, here we can conclude that combustion can be improved with the use of TF80 as compared to other fuels.

\section{Engine Performance Characteristics}

In this section, the effect of ternary fuel with different combinations on brake thermal efficiency and brake specific fuel consumption is discussed. The two parameters explain the energy conversion efficiency of the engine.

\section{Brake Thermal Efficiency}

For ternary fuel (MME20 blended with pentanol) and nanoparticle additives blended ternary fuel, it was evident that the BTE has increased with increase in load as illustrated in the figure 5 . The brake thermal efficiency of nanoparticle additives blended ternary fuel (TF80) was much greater when compared with other blends and also conventional diesel. Brake thermal efficiency of MME20 is minimum (at all loads) with higher levels of viscosity and density of esterified methyl ester. As compared to D100, the viscosity of MME20 is $52.82 \%$ higher resulting in minimum brake thermal efficiency of $24.1 \%$. It also shows partial burning of MME20 as compared to diesel. Brake thermal efficiency at all loads is seen to increase because of the presence of pentanol in Ternary Fuel. This is mostly due to sufficient oxygen molecules in pentanol resulting in better combustion. As brake thermal efficiency of ternary fuel is still lower, enhancement in the same can be sought with the addition of iron oxide nano additives in ternary fuel. When nanoparticle additives were mixed with ternary fuel $(40,80$ and $120 \mathrm{ppm})$ blend an increase of $1.58 \%, 1.62 \%$ and $2.34 \%$ was observed in brake thermal efficiency. This can be assigned to the finer combustion characteristics of nanoparticle additives, due to the reason that there might have occurred a 
refinement in the catalytic activity of nanoparticles. Simultaneously, as the evaporation rate is increased and physical delays are reduced which leads to improved BTE along with an increase in combustion efficiency (Raju et al. (2018), Kao et al. (2007) \& Shaafi \& Velraj (2015)) wherein the key attributes seem to be nanoparticles catalytic activity promoting primary droplets micro-explosion. More contact surface area of the NPs with high potential to store reactivity and energy, as explained by De Luca et al. (2005) and Yetter et al. (2009) which is also one of the main reasons for rise in brake thermal efficiency. Another reasonable cause for improvement in the engine is the positive effect of NP additives on HTR (heat transfer rate) due to its improved heat/mass transfer, radiative and conductive properties demonstrated by Tyagi et al. (2008). In comparison with TF40 and TF80, better thermal efficiency is observed at TF120 at various engine loads. These results are in accordance with the iron oxide nano additives inclusion in the blend with the increased thermal efficiency as mentioned in the open literature.

\section{Brake Specific Fuel Consumption (SFC)}

Figure 6 represents the variations in BSFC (specific fuel consumption) for MME20, ternary fuel blended with iron oxide nanoparticle additives and conventional diesel with load. When compared to conventional diesel fuel MME blend has less calorific value and higher viscosity leading to lesser fuel droplets atomization and vaporization rate so in order to maintain the same output power, more fuel is being consumed during the operation of mahua methyl ester blend 20. So, when compared with conventional diesel fuel Mahua methyl ester blend uses more fuel for the operation. The performance of the engine can be improved by the addition of nanoparticle additives to ternary fuel. As compared to MME20, BSFC for ternary fuel blended nano additives (TF40, TF80 and TF120) is found to be lower for all loads whereas, in case of plain diesel, it is higher. To have excellent combustion characteristics and better atomization results in blended fuels having iron oxide nanoparticles and thus observes the BSFC which is improved. Due to the inclusion of nanoparticles, there will be abundance oxygen to finish entire burning and due to the physical properties of the fuel, there will be lessening of BSFC owing to constructive outcomes of nanoparticles. Fuel consumption will be reduced as a result, if the friction power of the cylinder will decrease due to the reduction in the formation of carbon deposits by NP's. The BSFC becomes $0.34,0.33$ and $0.31 \mathrm{~kg} / \mathrm{kW}$-hr for TF40, TF80 and TF120 respectively when a fraction of $40 \mathrm{ppm}$, $80 \mathrm{ppm}$ and $120 \mathrm{ppm}$ along with ternary fuel is added with nanoparticles if the load is maximum and fuel consumption of MME20 becomes $0.355 \mathrm{~kg} / \mathrm{kW}$-hr. Similar to BTE profile, the energy consumption profile also tends to go down slightly after iron oxide nano additives in ternary fuel blend. This reduction may be due to high cetane number, less physical delay and high contact surface area of iron oxide nanoparticle. Also, TF120 consumed the least energy among all other blends. Probably due to the high heat released from complete combustion prompted through nano additives, improved spray penetration, lowered ID and higher evaporation rate, this reduced BSFC.

\section{Engine Exhaust Emission characteristics}


In this section, the effect of ternary fuel with different combinations on $\mathrm{CO}, \mathrm{HC}, \mathrm{NO}_{\mathrm{x}}$ and smoke opacity are discussed. The exhaust emissions are the reflection of combustion characteristics of the fuel in the engine. The appropriate combustion exhibits higher $\mathrm{NO}_{x}$, lower $\mathrm{HC}, \mathrm{CO}$ and smoke emissions.

\section{Carbon monoxide Emissions}

Figure 7 illustrates the variation of carbon monoxide emissions for various blends of fuel, clearly indicates that in comparison to plain diesel, nanoparticle additives blended ternary fuel blends outperforms it by emitting a significantly lesser quantity of $\mathrm{CO}$. The use of nanoparticle additives reduces ignition delay by advancing the fuel combustion inside the cylinder through speedy combustion reactions. However, if the nanoparticle additives usage is excluded, the combustion was observed to be partial in contrast to a fuel mixture with a proper ratio of fuel and air which resulted in high-quality complete combustion consequently producing less emissions of carbon monoxide. Apparently, due to the presence of high oxygen quantity, the rate of conversion from carbon dioxide to monoxide gets accelerated while using mahua methyl ester in an engine. When TFB is used for fueling the engine, the CO emissions are also observed to be reduced than MME20 at all load conditions. This reduction is due to the combustion enhancer, pentanol which amplifies the combustion process. The further addition of iron oxide nano additives in ternary fuel makes it more resistant to $\mathrm{CO}$ emission. The observations of $\mathrm{CO}$ emission by TF40, TF80, TF120 were $7.89 \%, 11.23 \%, 23.26 \%$ lower than TF. The reason behind this phenomenon is due to the high oxygen-bearing nature of iron oxide nanoparticle additives which helps in increasing the catalytic activity to oxidize the $\mathrm{CO}$ molecules. Additionally, the high reactivity of nano additives due to high contact surface area per volume reduces $\mathrm{CO}$ emissions through better combustion by lowering the ignition delay period.

\section{Hydrocarbon Emissions (UHC)}

At different loads and fuel blends, the variation in emissions of unburnt hydrocarbon (UHC) against load is presented in figure 8. To determine the emission behaviour of the engine UHC is also an important limitation. For all the engine loads, UHC emission is observed to be highest in D100 as compared to MME20 which emitted $6.84 \%, 10.36 \%, 11.31 \%, 9.49 \%$, and $3.54 \%$ of unburnt hydrocarbons. This trend matches with $\mathrm{CO}$ emission of MME20 with respect to plain diesel. The load rise also affects the UHC emission because of high air-fuel mixture generation in wall films and crevices (cold quench areas) and plenty of available fuel in the combustion zone. By adding nanoparticle additives in fuel blends, emission of hydrocarbon is reduced to a considerable extent (TF40, TF80 and TF120 emitted UHC 5.08\%, 6.78\%, and $7.56 \%$ less than TF). The combustion of fuel is further advanced by the presence of nanoparticle additives in the biodiesel blend due to the fact that it acts as a catalyst (oxidising nature) for enhancing the propagation of flame and hence reducing carbon activation temperature. The presence of sufficient oxygen atoms in ethyl alcohol to be supplied for complete burning of fuel makes it a blend with least HC emission. The UHC emission is restrained by each of these elements from biodiesel blends including nanoparticle additives. But interestingly, due to the high cetane number as well as oxygen content of biofuels, a quantitative rise in iron oxide nanoparticles in their blends were found to produce considerably 
less $\mathrm{HC}$ emission. At full load, ternary fuel shows lowest emission as compared to MME20 and D100 by $3.68 \%$ and $10.84 \%$ respectively.

\section{Nitrogen Oxides}

The variation of pure diesel, ternary fuel blended with nanoparticle additives and MME20 against load for NOx emission is illustrated in figure $9 . \mathrm{NO}_{\mathrm{x}}$ generation is a sophisticated process. A number of factors are responsible for $\mathrm{NO}_{\mathrm{x}}$ formation like working conditions, response time, combustion temperature, features of engine design, fuel properties etc. From the plot, it can be observed that diesel produced lesser $\mathrm{NO}_{\mathrm{x}}$ emissions than MME20. The reason could be the oxygen molecule presence which amplified the combustion process and thereby raising the combustion chamber temperature. Due to very high temperature inside the cylinder resulting through better combustion, $\mathrm{NO}_{\mathrm{x}}$ emissions raised for $\mathrm{MME20}$ by $12.46 \%$ when compared with D100 when the load is increased to maximum.

However, this property of high oxygen content helps in improving combustion and HRR in presence of high temperature inside cylinder but it's a threat to our environment as well. This NOx generation further increases due to its bulk modulus and injection of fuel happening earlier than usual. As per Zeldovich reaction mechanism, the NOx emissions increased because of the presence of iron oxide nanoparticle additives in ternary fuel which enhances the fuel burning inside the engine cylinder and it results in high temperature inside it. Thus, during combustion, NOx is higher compared to the conventional fuel. It is clear indications of higher HRR and cylinder pressure. TF40, TF80 and TF120 emitted NOx 7.67\%, 9.29\%, and $4.89 \%$ less than TF as shown in the figure 9. Finally, it can be observed that among all other test blends, minimum NOx emissions are given be TF40 (745ppm) at $100 \%$ load which is under standard limits.

\section{Smoke Opacity}

In Figure 10, for the various blends (nanoparticle additives blended ternary fuel, biodiesel blend, plain diesel) the smoke opacity variation in relation to load is illustrated. Highest smoke emission is observed in D100 for all the load conditions as compared to other fuels. Excess accumulation of fuel in the cylinder, deficiency of oxygen in the combustion rich areas and poor atomization result in the formation of smoke in $\mathrm{Cl}$ engines which is mostly due to partial combustion. Thus, it means that the low smoke emissions found in MME20 are due to better fuel oxidation inside the combustion chambers present near the fuel-rich zones. Further, smoke emissions were seen to be nominally reduced by $6.15 \%, 6.92 \%$ and $5.37 \%$ at full load by TF40, TF80 and TF120 respectively due to the blending of iron oxide nano additives in the TF as shown in the figure 10. It shows that as compared to diesel, smoke density considerably decreased by the use of ternary fuel blended with nanoparticle additives. It is speculated that this reduction is attributed to the presence of oxygen in the nanoparticle additives which encouraged better burning of the fuel mixture. While the smoke density rises for every blend at given loads there is a decrease in its density after adding more of the nanoparticle additives in the blends. The effect of 
nanoparticles addition is reflected through better ignition characteristics, shorter ignition delay and high evaporation rate. The lower smoke emission is probably due to the lower delay period due to which before ignition, surplus fuel is collected inside the cylinder making sure that combustion rate is high enough and better fuel-air mix is facilitated.

\section{Ignition Delay}

The delay period, commonly known as the ignition delay period is the time period from the start of fuel injection to the initiation of combustion. It also indicates the chemical as well as the physical delay of the fuel. The ignition delay suggests fuel mixing and atomization at the final stage, while the full precombustion process is shown at the initial stage. Depending on engine load for various fuel blends the change in ignition delay is depicted in figure 11. The highest ignition delay is observed in the D100 at all loads. But for lower loads TF40 and TF120 showed a similar delay profile. The reason behind this was mainly due to the less viscosity, high cetane number, density and better fuel mix rate. The next blend having lower delay period was TF80 due to its low compressibility factor, high cetane number and biodiesel composition. Also, the addition of iron oxide nanoparticles in the ternary fuel reduced the delay period as compared to D100. The reason behind low delay period is attributed to better fuel atomization through high surface tension and calorific range of the blend. Also, carbon chain molecule formation is hindered by the addition of iron oxide nano additives and pentanol which tends to rise the latent heat of fuel blends.

The figure 12 illustrates mass fraction burnt deviation w.r.t. crank angle for all blends. Due to the absence of oxygen in diesel, it showed a low range MFB for all crank angles compared to other blends. Irregular MFB trend has been observed for MME20 for all crank angles due to null atomization effect and availability of more fuel-rich zones. The addition of high concentrations of nanoparticle additives and pentanol can be customized for TF with additives and TF to achieve a mass fraction burnt spectrum (customary) in the blend at all crank angles.

\section{Trade-off (BSFC- BTE- NOx)}

The detrimental effects of soot and NOx are well known to everyone. They cause a plethora of respiratory illness and degrade the environment by causing global warming through smog formation. Furthermore, a fuel which is consumed in lesser quantity by the engine is one of the factors to choose a fuel; another reason being the depleting fuel reserves. Thus, to get a clearer picture, a trade-off study is required for comparing emission and performance of engines using various fuels with respect to SFC, brake thermal efficiency and NOx emission. It also gives scope for further explanation of intrinsic issues regarding the above. Figure 13 shows the $20 \%$ to $100 \%$ load trade-off for different combinations of fuel (MME20 (80\% diesel fuel + 20\% Mahua methyl ester), Ternary fuel (pentanol $10 \%+$ MME20\%+ diesel $70 \%$ ), Ternary fuel 40 (Ternary fuel mixed with iron oxide additives of $40 \mathrm{ppm}$ ), Ternary fuel 80 (Ternary fuel mixed with 80 ppm iron oxide additives) and Ternary fuel 120(Ternary fuel mixed with iron oxide additives of $120 \mathrm{ppm}$ )). It can be noticed clearly that the trade-off shifts to the extreme left corner (minimum fuel consumption) from extreme right corner (maximum fuel consumption). From the graph, the TF120 is seen to push the 
trade-off to a high-NOx emission zone and BTE with a reduction of BSFC. MME20 fuel operation reduces the equivalent BSFC along with NOx emission. Of the other blends, ternary blend produces lesser NOx and more BTE. When the load is increased to $40 \%$, the TF120 blends the smoke opacity and equivalent-BSFC reduction is seen which is indicated through the shifting of trade-off zone near to origin. Based on the trade-off pattern for the fuel sample considered, the following results can be concluded (1) Whenever the percentage of ternary fuel blended with iron oxide additives got increased, it is seen that BSFC decreases but when BTE rises NOx also goes up (2) On the other hand, TF120 shows high emission of NOx and BTE but relatively low BSFC as portrayed in the top area of the graph (3) Interestingly, TF80 shows the optimum trade-off zone with higher BTE and lower BSFC and lowest NOx emission from the current study.

\section{Conclusion}

The present work is focussed on the influence of ternary fuel blended with iron oxide nano additives, D100 and MME20 biodiesel blends are studied for their effect on engine emission, performance and combustion characteristics. Following conclusions are drawn based on extensive experimental study.

- TF (Ternary fuel) is obtained by mixing $10 \%$ pentanol, $20 \%$ MME biodiesel and $70 \%$ diesel together. High NOx and BSEC were observed for the blend than Plain diesel.

- Due to a positive impact on fuel blended with nanoparticle additives, BSFC of TF80 and TF120 blend was found to significantly decreased when compared with esterified MME20.

- At full load, smoke, NO, CO and HC emissions were found to be lower in TF120 by $6.92 \%, 9.39 \%$, $11.24 \%$ and $5.69 \%$ while BTE increased to $7.8 \%$ and BSFC decreased to $4.93 \%$ when compared with ternary fuel (TF).

- Ternary fuel blended nanoparticle additives quantity increase in the blend is proportional to HRR and cylinder pressure. This rise could be due to high surface contact area/volume of iron oxide nanoparticles which result in high catalytic activity.

- In this analysis, the trade-off study shows the effectiveness of TF120 in optimizing the emission parameters (NOx) to a certain standard level and decreasing the SFC as well.

- In the analysis, it was observed that due to iron oxide nano-additives high surfaces area in the fuel blend, the chemical reaction for combustion takes place very fast reducing the ignition delay and hence a complete combustion occurs. Thus, it was concluded that even though ternary fuel performs better, it can even be enhanced by blending the iron oxide nanoparticles in it.

From the above novel analysis, it is clear that to increase the engine performance and to control emission ternary fuel blended nanoparticle additives plays a major role. However, studies are still in the process to reduce unburnt nanoparticles through exhaust traps which could be a serious threat to the environment.

\section{Declarations}


Author contributions

Prabhu Kishore Nutakki: Conceptualization, methodology, writing, review and editing; S.K.Gugulothu: Formal analysis and investigation, writing original draft and preparation; J. Ramachander: Formal Analysis; M.Sivasurya: Formal analysis.

Data Availability: All data generated or analyzed during this study are included in this article.

\section{Compliance with ethical standards}

The present study work was not conducted on human or experimental animals where national or international guidelines are used for the protection of human subjects and animal welfare.

Ethical Approval: Not applicable

Consent to participate: Not applicable

Consent for publication: We confirm that the manuscript has been read and approved by all named authors and that there are no other persons who satisfied the criteria for authorship but are not listed. We further confirm that all the authors listed in the manuscript has been approved by all of us.

Competing interests: The authors declare that they have no competing interests.

Funding: No funding has been received

\section{References}

1. Ashok, B., A. K. Jeevanantham, K. Prabhu, Pratik M. Shirude, Datta D. Shinde, Nikhil S. Nadgauda, and C. Karthick. "Multi-Objective Optimization on Vibration and Noise Characteristics of Light Duty Biofuel Powered Engine at Idling Condition Using Response Surface Methodology." Journal of Energy Resources Technology 143, no. 4 (2020).

2. Barabas, I., Todoruţ, A. and Băldean, D., 2010. Performance and emission characteristics of an Cl engine fueled with diesel-biodiesel-bioethanol blends. Fuel, 89(12), pp.3827-3832.

3. Bhowmik, Subrata, Rajsekhar Panua, Durbadal Debroy, and Abhishek Paul. "Artificial neural network prediction of diesel engine performance and emission fueled with diesel-kerosene-ethanol blends: a fuzzy-based optimization." Journal of Energy Resources Technology 139, no. 4 (2017).

4. Bhowmik, Subrata, Rajsekhar Panua, Subrata Kumar Ghosh, Durbadal Debroy, and Abhishek Paul. "A comparative study of Artificial Intelligence based models to predict performance and emission characteristics of a single cylinder Diesel engine fueled with Diesosenol." Journal of Thermal Science and Engineering Applications 10, no. 4 (2018).

5. Charoensaeng, A., Khaodhiar, S., Sabatini, D.A. and Arpornpong, N., 2018. Exhaust emissions of a diesel engine using ethanol-in-palm oil/diesel microemulsion-based biofuels. Environmental 
Engineering Research, 23(3), pp.242-249.

6. Chen, A.F., Adzmi, M.A., Adam, A., Othman, M.F., Kamaruzzaman, M.K. and Mrwan, A.G., 2018. Combustion characteristics, engine performances and emissions of a diesel engine using nanoparticle-diesel fuel blends with aluminium oxide, carbon nanotubes and silicon oxide. Energy Conversion and Management, 171, pp.461-477.

7. Chockalingam, S.R., Kumar, M. and Pauldoss, P., 2017. Effective application of ethanol in diesel engines. International Journal of Green Energy, 14(12), pp.1027-1033.

8. Datta, A. and Mandal, B.K., 2014. Use of Jatropha biodiesel as a future sustainable fuel. Energy Technology \& Policy, 1(1), pp.8-14.

9. De Luca, L.T., Galfetti, L., Severini, F., Meda, L., Marra, G., Vorozhtsov, A.B., Sedoi, V.S. and Babuk, V.A., 2005. Burning of nano-aluminized composite rocket propellants. Combustion, Explosion and Shock Waves, 47(6), pp.680-692.

10. Dogan, B., Cakmak, A., Yesilyurt, M.K. and Erol, D., 2020. Investigation on 1-heptanol as an oxygenated additive with diesel fuel for compression-ignition engine applications: An approach in terms of energy, exergy, exergoeconomic, enviroeconomic, and sustainability analyses. Fuel, 275, p.117973.

11. El-Seesy, A.I., Attia, A.M. and El-Batsh, H.M., 2018. The effect of Aluminum oxide nanoparticles addition with Jojoba methyl ester-diesel fuel blend on a diesel engine performance, combustion and emission characteristics. Fuel, 224, pp.147-166.

12. Fang, Q., Fang, J., Zhuang, J. and Huang, Z., 2013. Effects of ethanol-diesel-biodiesel blends on combustion and emissions in premixed low temperature combustion. Applied Thermal Engineering, 54(2), pp.541-548.

13. Ghadikolaei, M.A., Yung, K.F., Cheung, C.S. and Lau, P.C., 2019. Chemical properties and composition of PM emitted from a diesel engine fueled with ternary fuel (diesel-biodiesel-ethanol) in blended and fumigation modes. Fuel, 251, pp.368-382.

14. Gugulothu, S.K. and Reddy, K.H.C., 2016. CFD simulation of in-cylinder flow on different piston bowl geometries in a DI diesel engine. Journal of Applied Fluid Mechanics, 9(3), pp.1147-1155.

15. Gugulothu, S.K., 2020. Performance and emission analysis of SOME (Schleichera oleosa oil methyl ester) on DI diesel engine. SN Applied Sciences, 2(4), pp.1-13.

16. Gugulothu, S.K., Kishore, N.P., Babu, V.P. and Sapre, G., 2019. Cfd Analysis on Different Piston Bowl Geometries by Using Split Injection Techniques. Acta Mechanica Malaysia, 2(1), pp.23-28.

17. Gugulothu, S.K., Ramachander, J. and Kumar, A.K., 2021. Predicting the engine trade-off study and performance characteristics using different blends of methyl Ester fish oil and higher alcohol with aid of artificial neural network based multi objective optimization. Heat and Mass Transfer, pp.1-18.

18. Hosseini, S.H., Taghizadeh-Alisaraei, A., Ghobadian, B. and Abbaszadeh-Mayvan, A., 2017. Effect of added alumina as nano-catalyst to diesel-biodiesel blends on performance and emission characteristics of Cl engine. Energy, 124, pp.543-552. 
19. Hulwan, D.B. and Joshi, S.V., 2011. Performance, emission and combustion characteristic of a multicylinder DI diesel engine running on diesel-ethanol-biodiesel blends of high ethanol content. Applied Energy, 88(12), pp.5042-5055.

20. Kao, M.J., Ting, C.C., Lin, B.F. and Tsung, T.T., 2008. Aqueous aluminum nanofluid combustion in diesel fuel. Journal of testing and evaluation, 36(2), pp.186-190.

21. Kapoor, Mayank, Narendra Kumar, Ajay Singh Verma, Gaurav Gautam, and Aditya Kumar Padap. "Performance and Emission Analysis of Compression Ignition Engine with Neem Methyl Ester Mixed with Cerium Oxide (CeO2) Nanoparticles." Journal of Energy Resources Technology 142, no. 8 (2020).

22. Kumar Sharma, Pushpendra, Dilip Sharma, Shyam Lal Soni, and Amit Jhalani. "Characterization of the nonroad modified diesel engine using a novel entropy-VIKOR approach: experimental investigation and numerical simulation." Journal of Energy Resources Technology 141, no. 8 (2019).

23. Kumar, V.N. and Gugulothu, S.K., 2020. Influence of Nanofluid In Thermal and Mechanical Properties of Nr Alumina Polymer Nanocomposites. Composites Part C: Open Access, p.100094.

24. Li, X., Xu, Z., Guan, C. and Huang, Z., 2014. Particle size distributions and OC, EC emissions from a diesel engine with the application of in-cylinder emission control strategies. Fuel, 121, pp.20-26.

25. Lin, J., Gaustad, G. and Trabold, T.A., 2013. Profit and policy implications of producing biodieselethanol-diesel fuel blends to specification. Applied energy, 104, pp.936-944.

26. Marri, Vinod Babu, K. Madhu Murthy, and G. Amba Prasad Rao. "Optimization of operating parameters of an off-road automotive diesel engine running at highway drive conditions using Response Surface Methodology." Journal of Energy Resources Technology (2020): 1-48.

27. Nour, M., El-Seesy, A.I., Abdel-Rahman, A.K. and Bady, M., 2018. Influence of adding aluminum oxide nanoparticles to diesterol blends on the combustion and exhaust emission characteristics of a diesel engine. Experimental Thermal and Fluid Science, 98, pp.634-644.

28. Prabu, A. and Anand, R.B., 2016. Emission control strategy by adding alumina and cerium oxide nano particle in biodiesel. Journal of the Energy Institute, 89(3), pp.366-372.

29. Qi, D.H., Chen, H., Geng, L.M. and Bian, Y.Z., 2011. Effect of diethyl ether and ethanol additives on the combustion and emission characteristics of biodiesel-diesel blended fuel engine. Renewable energy, 36(4), pp.1252-1258.

30. Raju, V.D., Kishore, P.S., Nanthagopal, K. and Ashok, B., 2018. An experimental study on the effect of nanoparticles with novel tamarind seed methyl ester for diesel engine applications. Energy conversion and management, 164, pp.655-666.

31. Rakopoulos, D.C., Rakopoulos, C.D., Kakaras, E.C. and Giakoumis, E.G., 2008. Effects of ethanoldiesel fuel blends on the performance and exhaust emissions of heavy duty DI diesel engine. Energy conversion and management, 49(11), pp.3155-3162.

32. Ramachander, J., Gugulothu, S.K., Sastry, G.R.K., Panda, J.K. and Surya, M.S., Performance and emission predictions of a CRDI engine powered with diesel fuel: A combined study of injection 
parameters variation and Box-Behnken response surface methodology-based optimization. Fuel, 290, p.120069.

33. Sandalcı, T., Karagöz, Y., Orak, E. and Yüksek, L., 2014. An experimental investigation of ethanoldiesel blends on performance and exhaust emissions of diesel engines. Advances in Mechanical Engineering, 6, p.409739.

34. Selvan, V.A.M., Anand, R.B. and Udayakumar, M., 2009. Effects of cerium oxide nanoparticle addition in diesel and diesel-biodiesel-ethanol blends on the performance and emission characteristics of a $\mathrm{Cl}$ engine. J Eng App/ Sci, 4(7), pp.1819-6608.

35. Shaafi, T. and Velraj, R., 2015. Influence of alumina nanoparticles, ethanol and isopropanol blend as additive with diesel-soybean biodiesel blend fuel: Combustion, engine performance and emissions. Renewable Energy, 80, pp.655-663.

36. Singh, P., Chauhan, S.R. and Kumar, N., 2016. A review on methodology for complete elimination of diesel from $\mathrm{Cl}$ engines using mixed feedstock. Renewable and Sustainable Energy Reviews, 57, pp.1110-1125.

37. Singh, P., Tiwari, S.K., Singh, R. and Kumar, N., 2017. Modification in combustion chamber geometry of $\mathrm{Cl}$ engines for suitability of biodiesel: A review. Renewable and Sustainable Energy Reviews, 79, pp.1016-1033.

38. Sivakumar, M., Sundaram, N.S. and Thasthagir, M.H.S., 2018. Effect of aluminium oxide nanoparticles blended pongamia methyl ester on performance, combustion and emission characteristics of diesel engine. Renewable Energy, 116, pp.518-526.

39. Soudagar, M.E.M., Nik-Ghazali, N.N., Kalam, M.A., Badruddin, I.A., Banapurmath, N.R. and Akram, N., 2018. The effect of nano-additives in diesel-biodiesel fuel blends: A comprehensive review on stability, engine performance and emission characteristics. Energy Conversion and Management, 178, pp.146-177.

40. Surya, M.S., Prasanthi, G. and Gugulothu, S.K., 2021. Investigation of Mechanical and Wear Behaviour of Al7075/SiC Composites Using Response Surface Methodology. Silicon, pp.1-11.

41. Tyagi, H., Phelan, P.E., Prasher, R., Peck, R., Lee, T., Pacheco, J.R. and Arentzen, P., 2008. Increased hot-plate ignition probability for nanoparticle-laden diesel fuel. Nano letters, 8(5), pp.1410-1416.

42. Venu, H. and Madhavan, V., 2016. Effect of Al2O3 nanoparticles in biodiesel-diesel-ethanol blends at various injection strategies: Performance, combustion and emission characteristics. Fuel, 186, pp.176-189.

43. Venu, H. and Madhavan, V., 2017. Effect of diethyl ether and Al 203 nano additives in dieselbiodiesel-ethanol blends: Performance, combustion and emission characteristics. Journal of Mechanical Science and Technology, 31(1), pp.409-420.

44. Wu, Q., Xie, X., Wang, Y. and Roskilly, T., 2018. Effect of carbon coated aluminum nanoparticles as additive to biodiesel-diesel blends on performance and emission characteristics of diesel engine. Applied Energy, 221, pp.597-604. 
45. Yesilyurt, M.K. and Arslan, M., 2018. Analysis of the fuel injection pressure effects on energy and exergy efficiencies of a diesel engine operating with biodiesel. Biofuels.

46. Yesilyurt, M.K. and Aydin, M., 2020. Experimental investigation on the performance, combustion and exhaust emission characteristics of a compression-ignition engine fueled with cottonseed oil biodiesel/diethyl ether/diesel fuel blends. Energy Conversion and Management, 205, p.112355.

47. Yesilyurt, M.K., 2019. The effects of the fuel injection pressure on the performance and emission characteristics of a diesel engine fuelled with waste cooking oil biodiesel-diesel blends. Renewable energy, 132, pp.649-666.

48. Yesilyurt, M.K., Aydin, M., Yilbasi, Z. and Arslan, M., 2020. Investigation on the structural effects of the addition of alcohols having various chain lengths into the vegetable oil-biodiesel-diesel fuel blends: An attempt for improving the performance, combustion, and exhaust emission characteristics of a compression ignition engine. Fuel, 269, p.117455.

49. Yesilyurt, M.K., Yilbasi, Z. and Aydin, M., 2020. The performance, emissions, and combustion characteristics of an unmodified diesel engine running on the ternary blends of pentanol/safflower oil biodiesel/diesel fuel. Journal of Thermal Analysis and Calorimetry, pp.1-40.

50. Yetter, R.A., Risha, G.A. and Son, S.F., 2009. Metal particle combustion and nanotechnology. Proceedings of the Combustion Institute, 32(2), pp.1819-1838.

51. Yilmaz, N., Vigil, F.M., Donaldson, A.B. and Darabseh, T., 2014. Investigation of Cl engine emissions in biodiesel-ethanol-diesel blends as a function of ethanol concentration. Fuel, 115, pp.790-793.

\section{Figures}




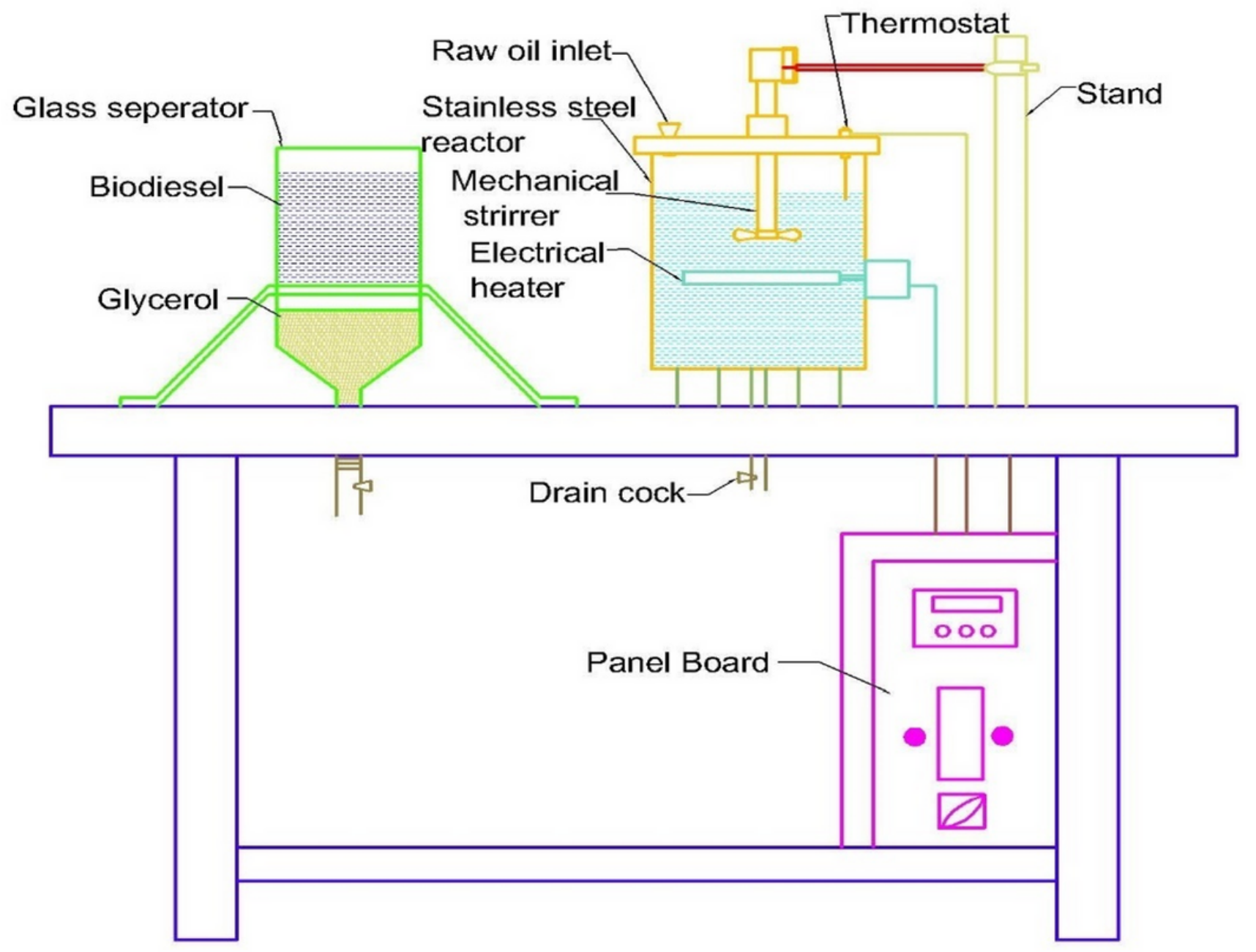

Figure 1

Transesterification process (Biodiesel plant) 


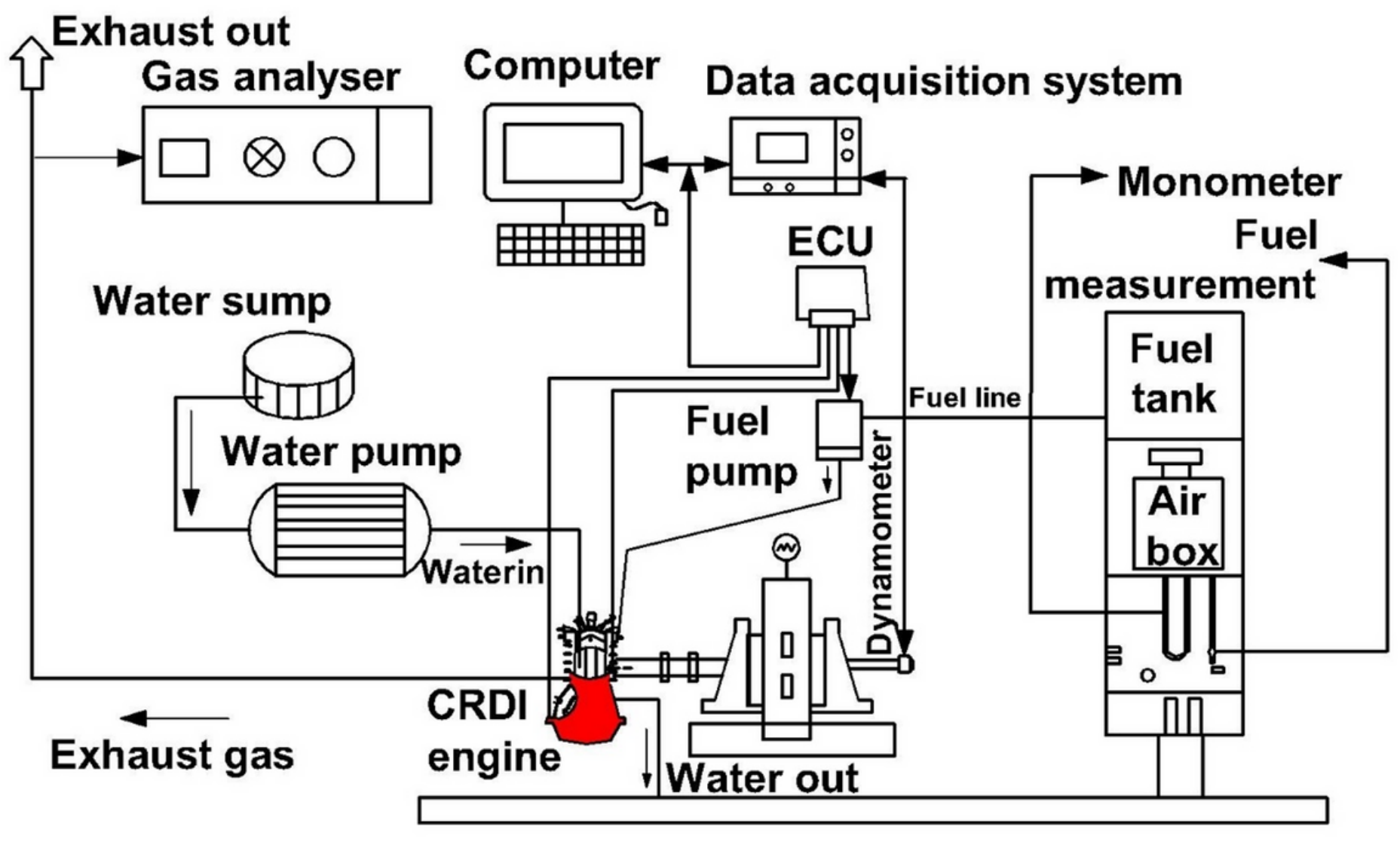

Figure 2

Schematic of Experimental layout 


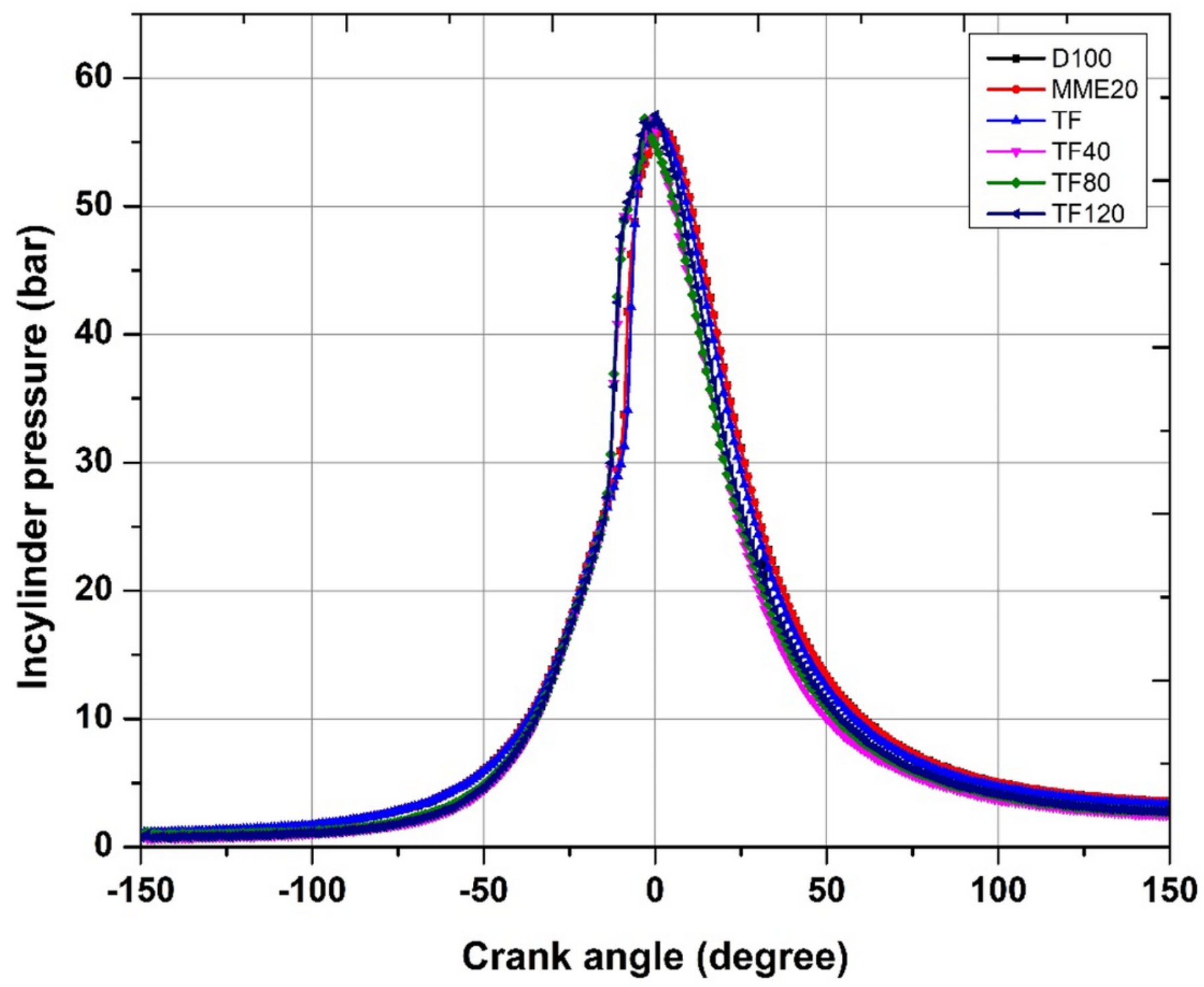

Figure 3

Variation of in-cylinder pressure against crank angle for different fuels 


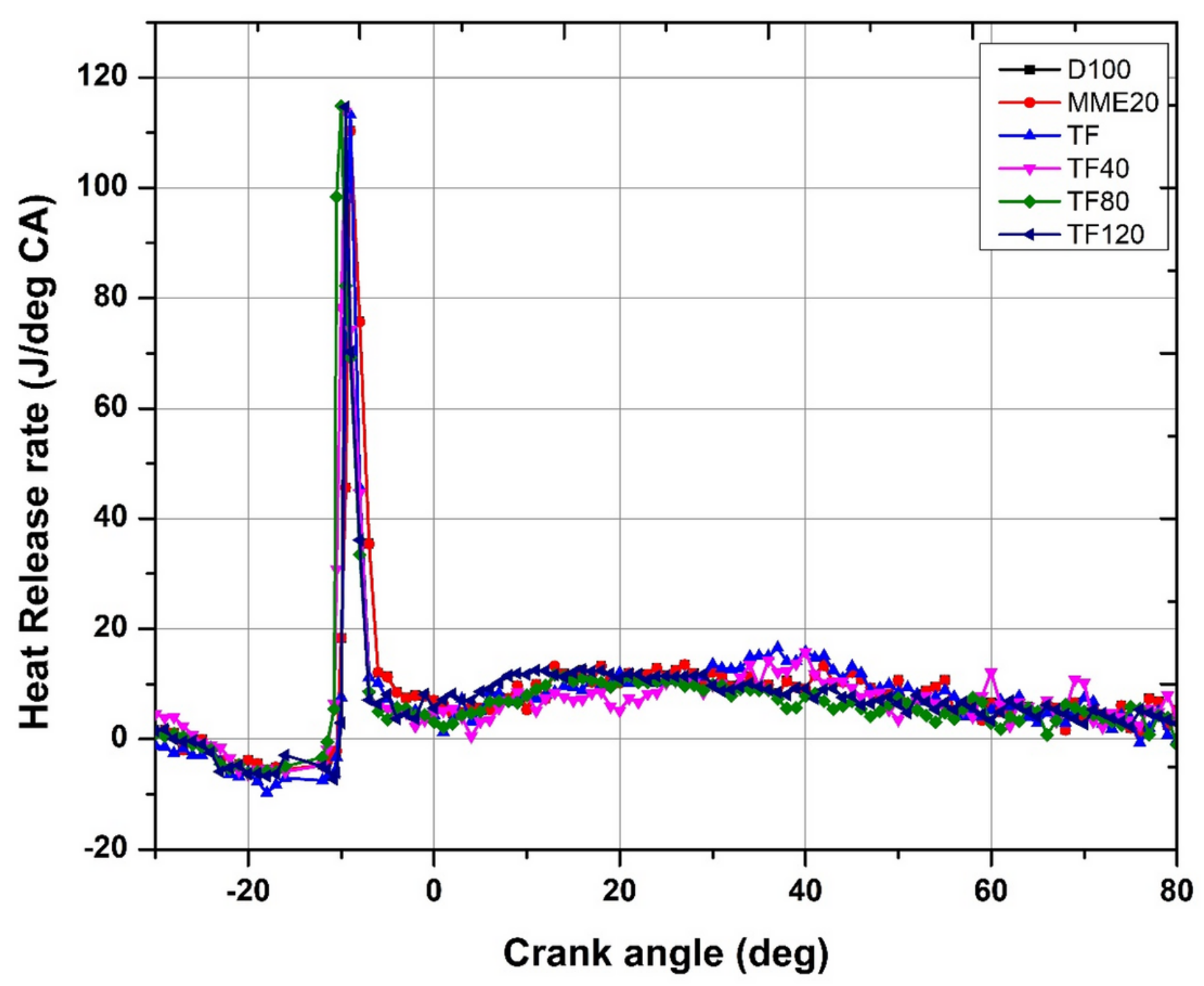

Figure 4

Variation of heat release rate against crank angle for different fuels 


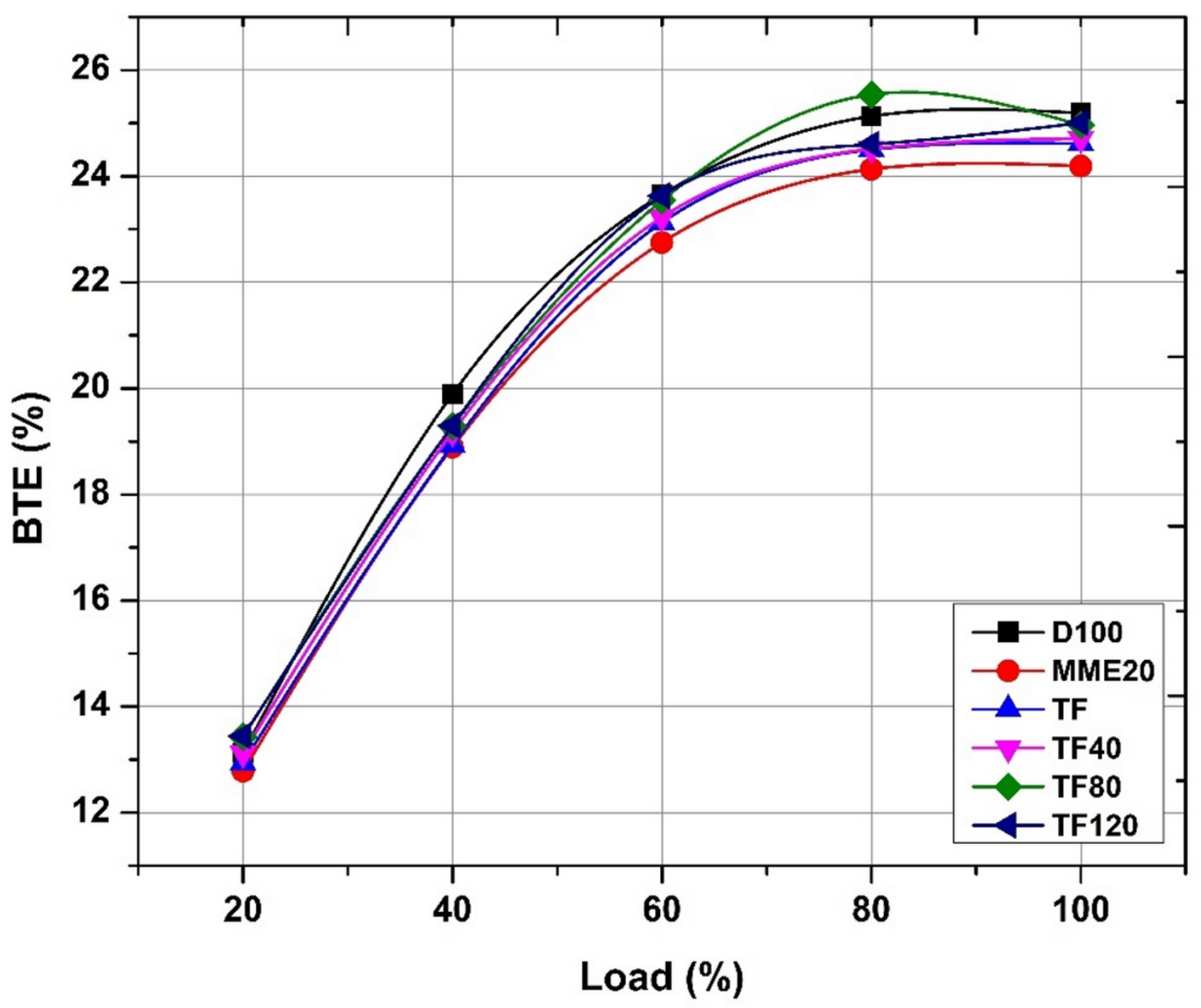

Figure 5

Variation of Brake thermal efficiency against load for different fuels 


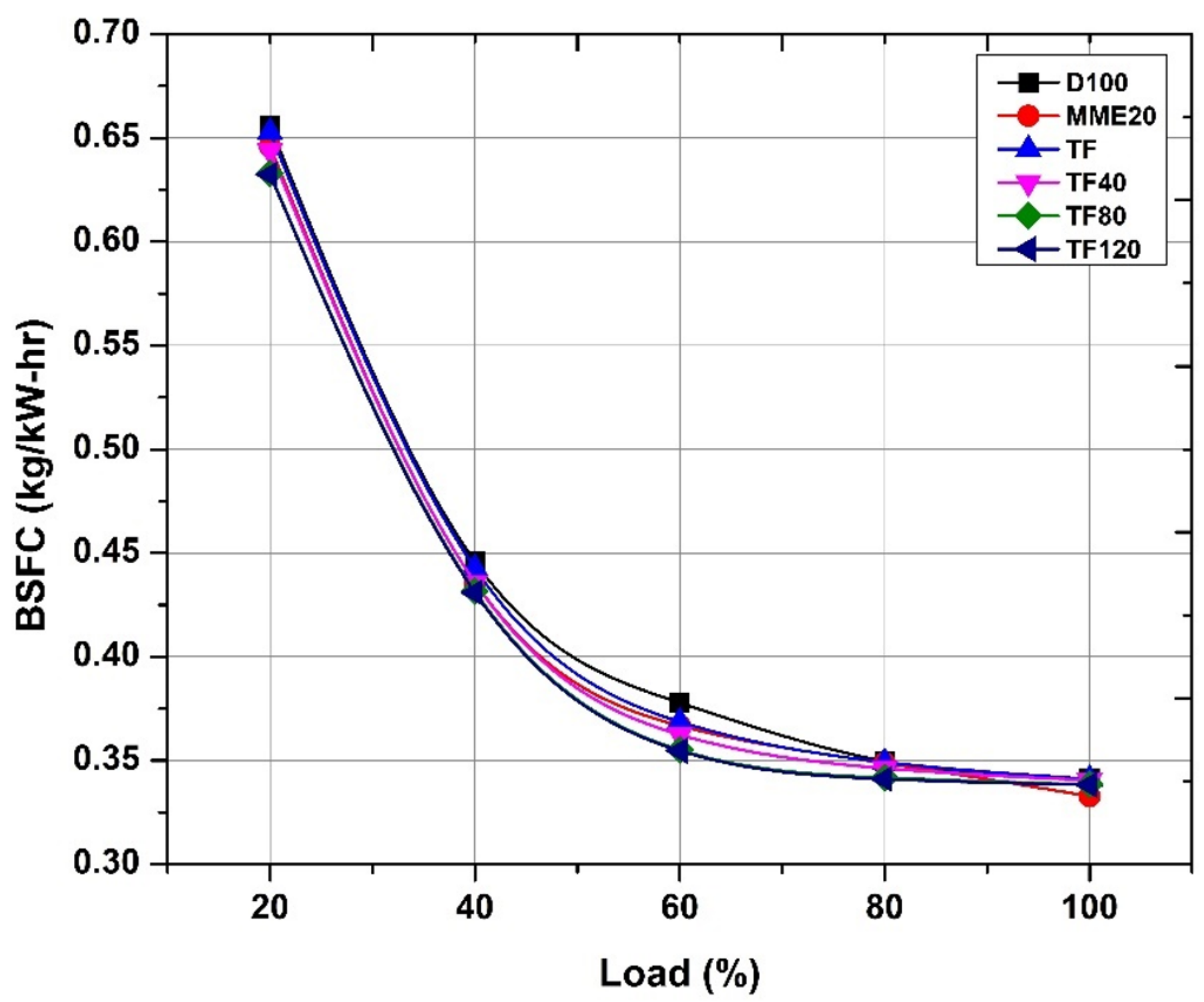

Figure 6

Variation of Brake specific fuel consumption against load for different fuels 


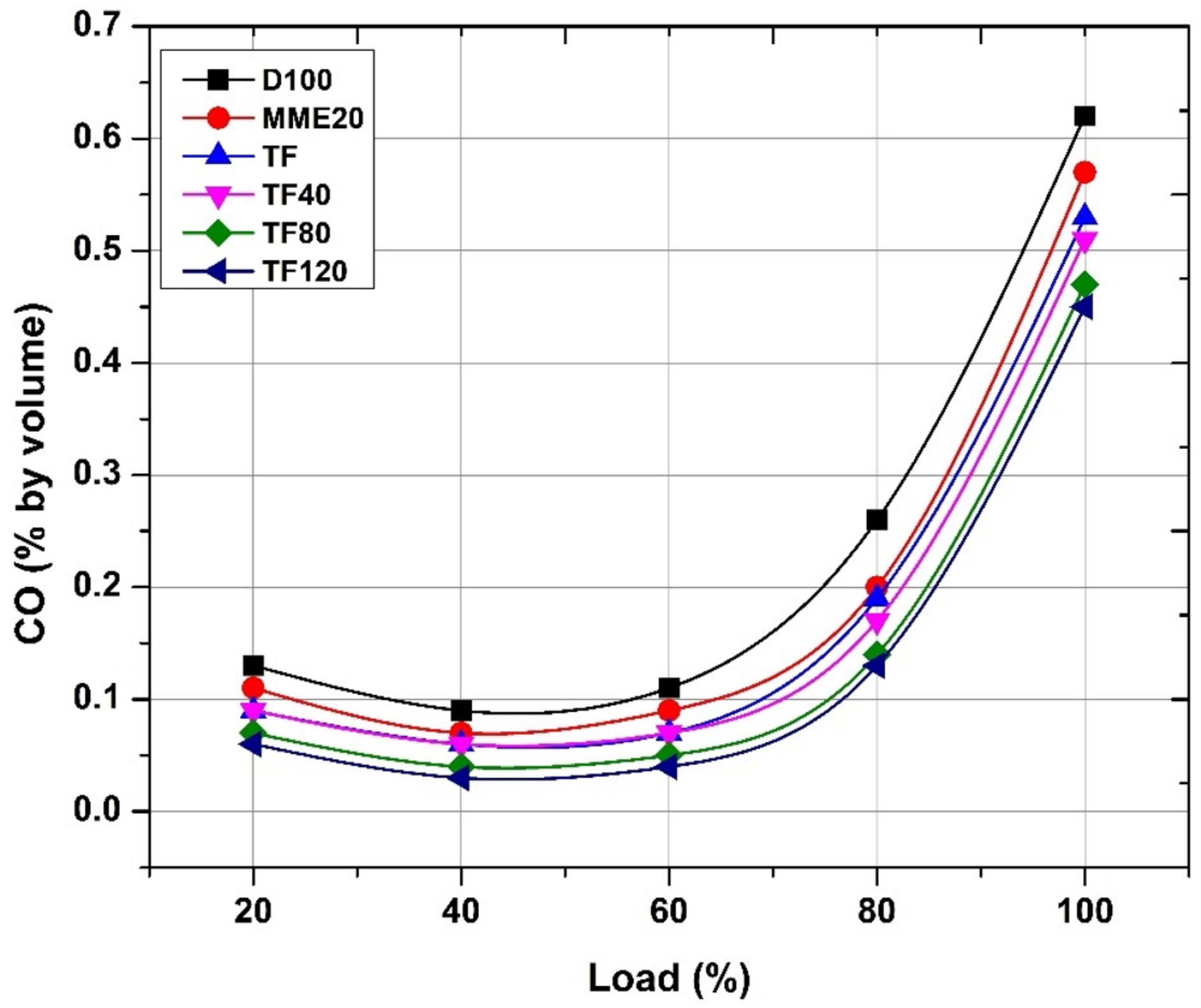

Figure 7

Variation of carbon monoxide emissions against load for different fuels 


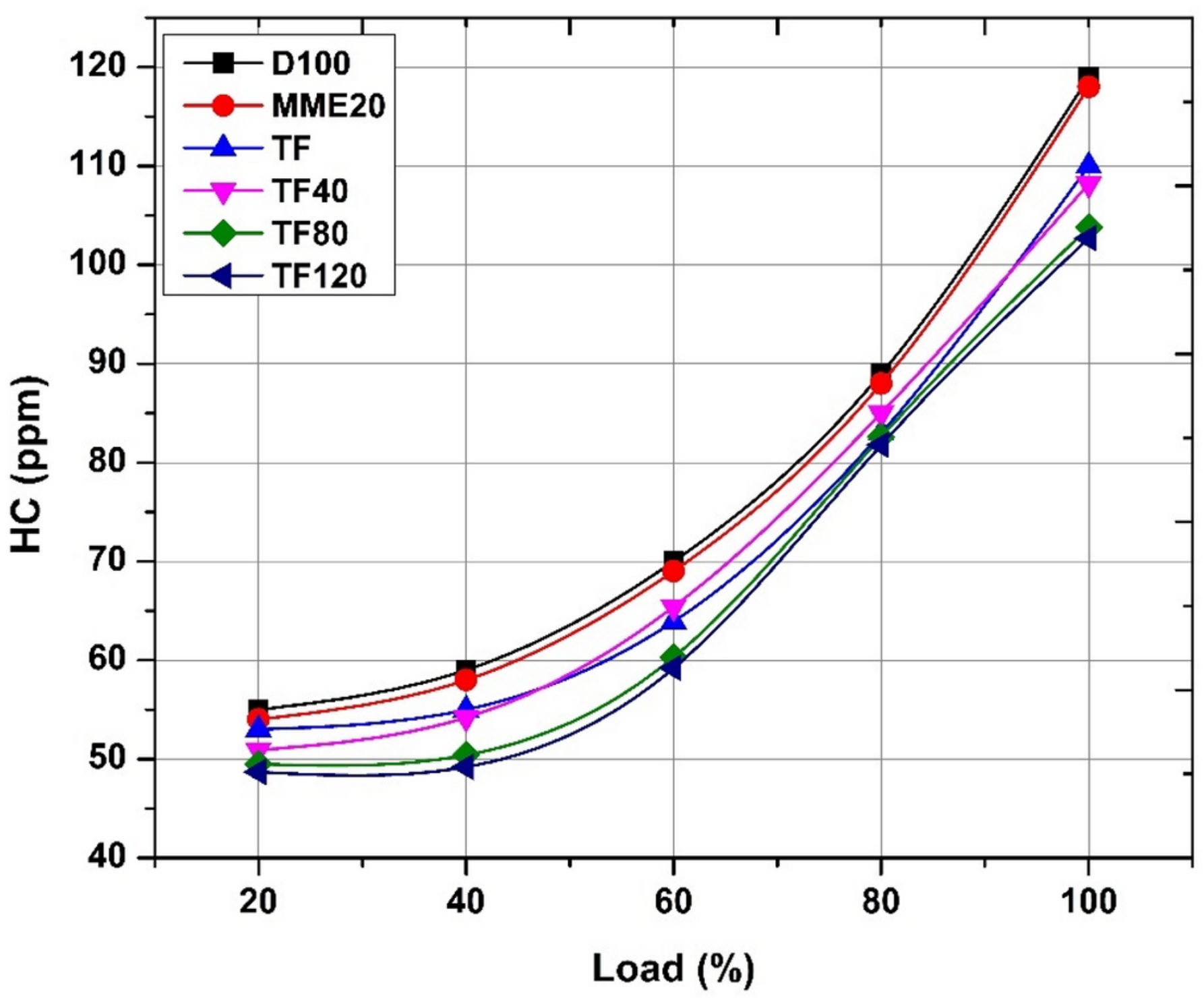

Figure 8

Variation of unburnt hydrocarbon against load against different fuels 


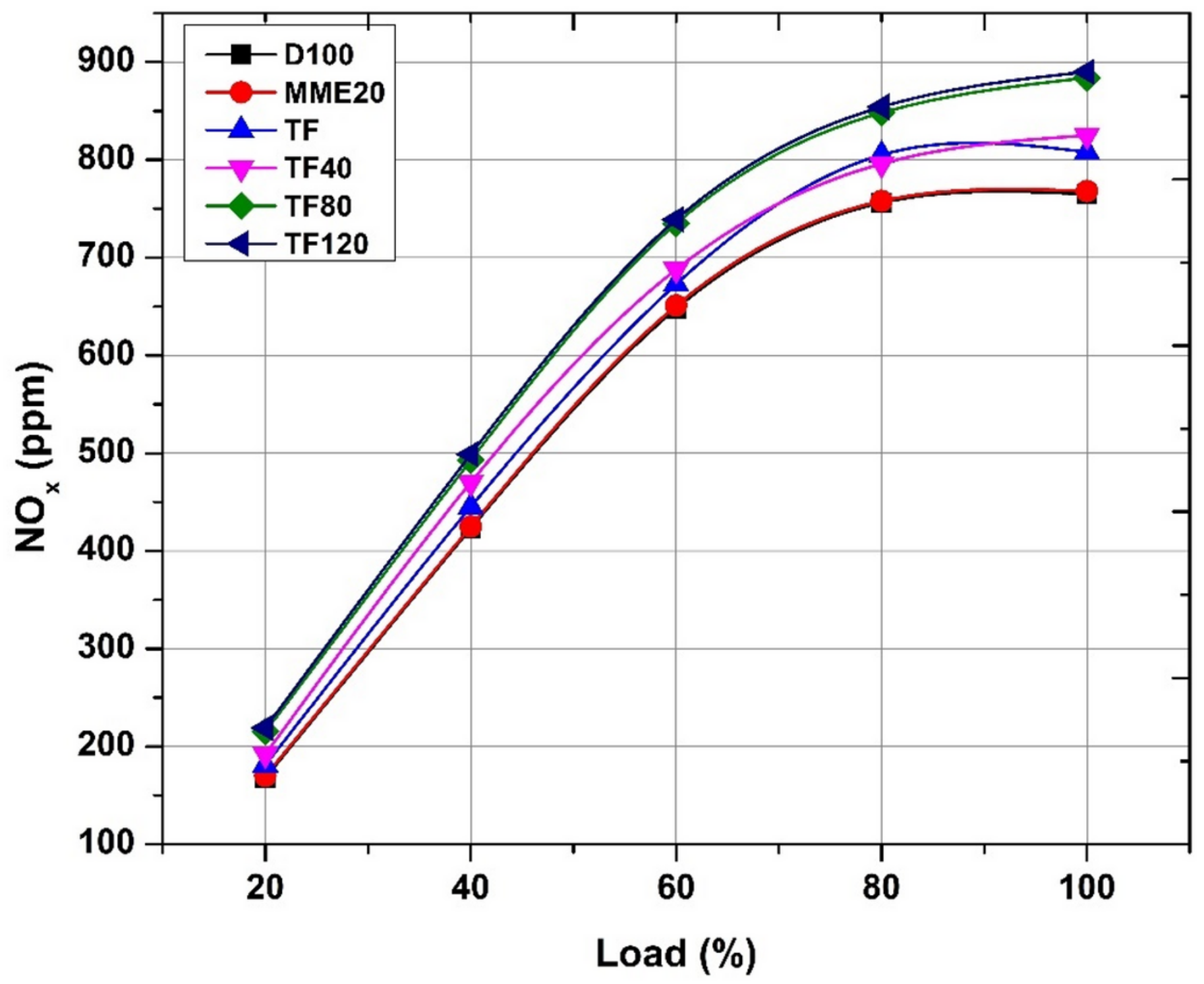

Figure 9

Variation of oxides of nitrogen against load for different fuels 


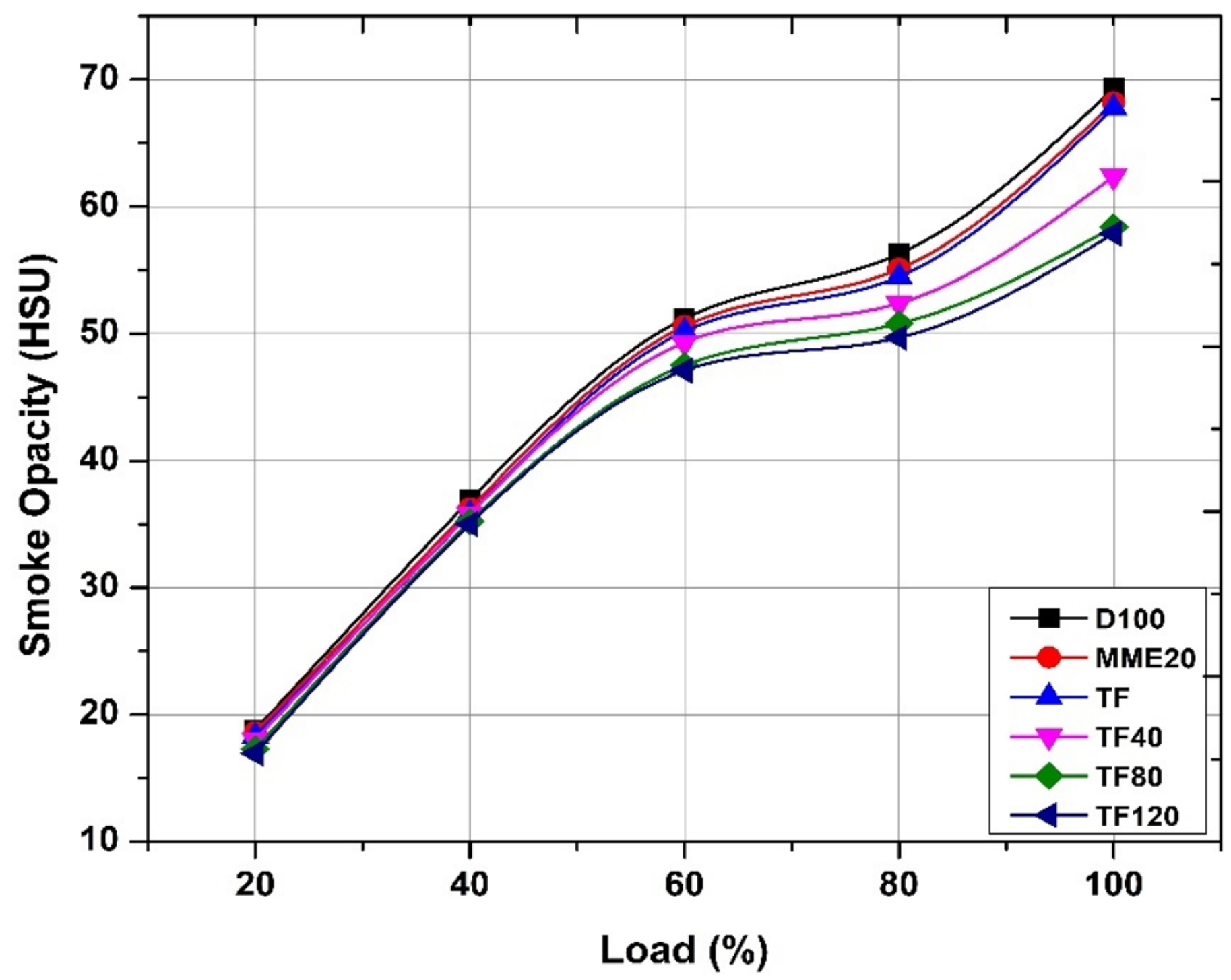

Figure 10

Variation of smoke opacity against load for different fuels 


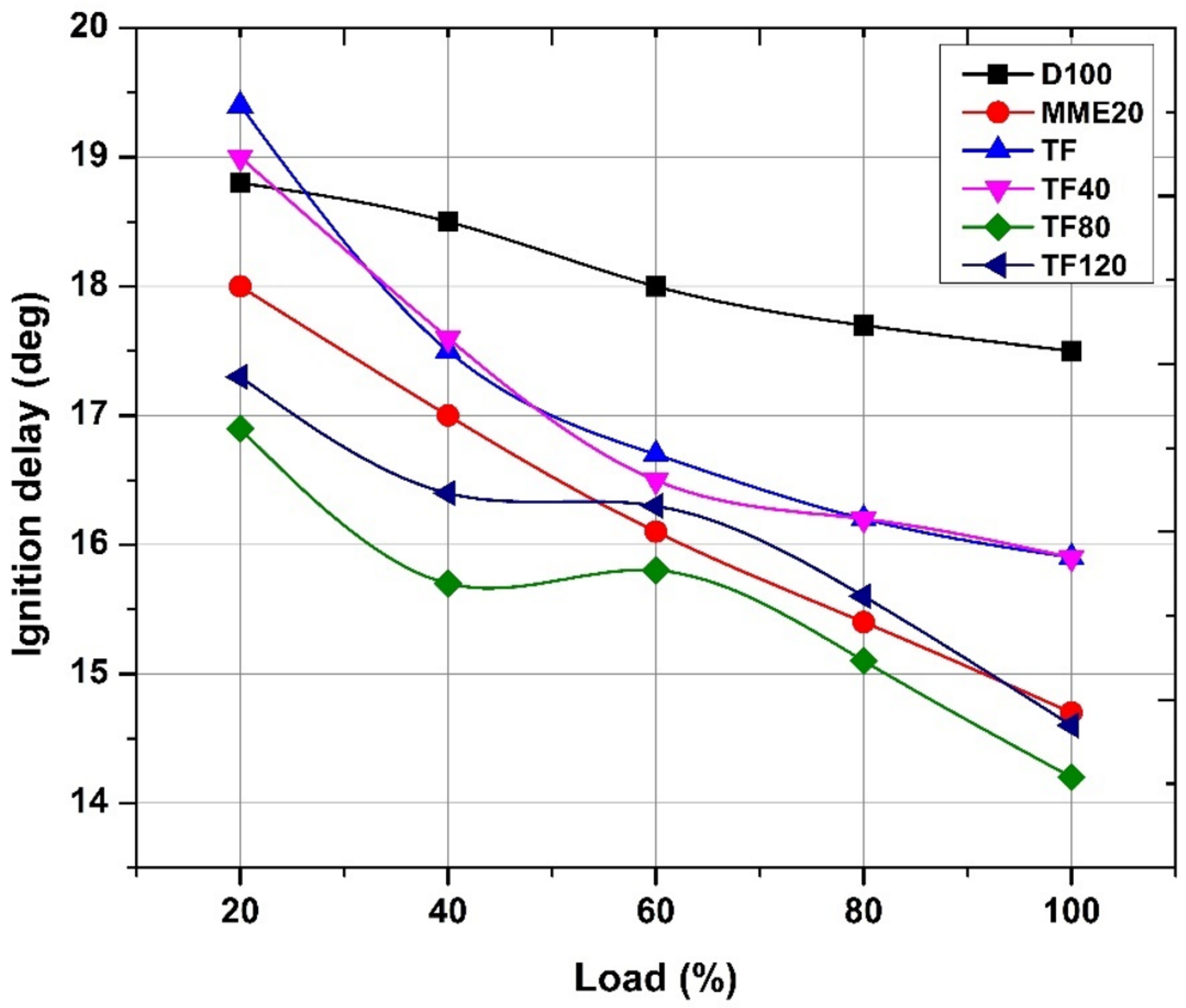

Figure 11

Variation of ignition delay against load for different fuels 


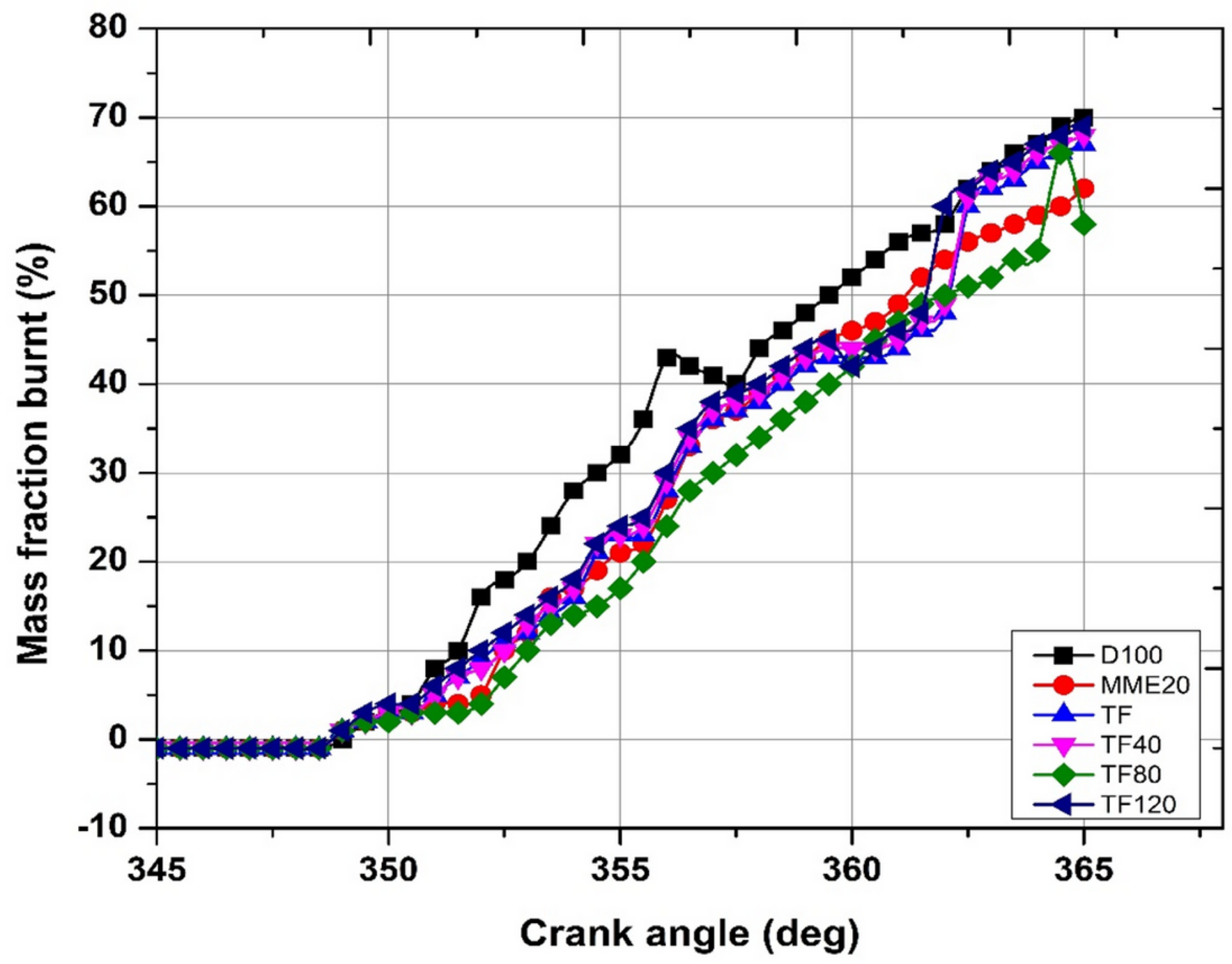

Figure 12

Variation of mass fraction burnt against crank angle for different fuels 


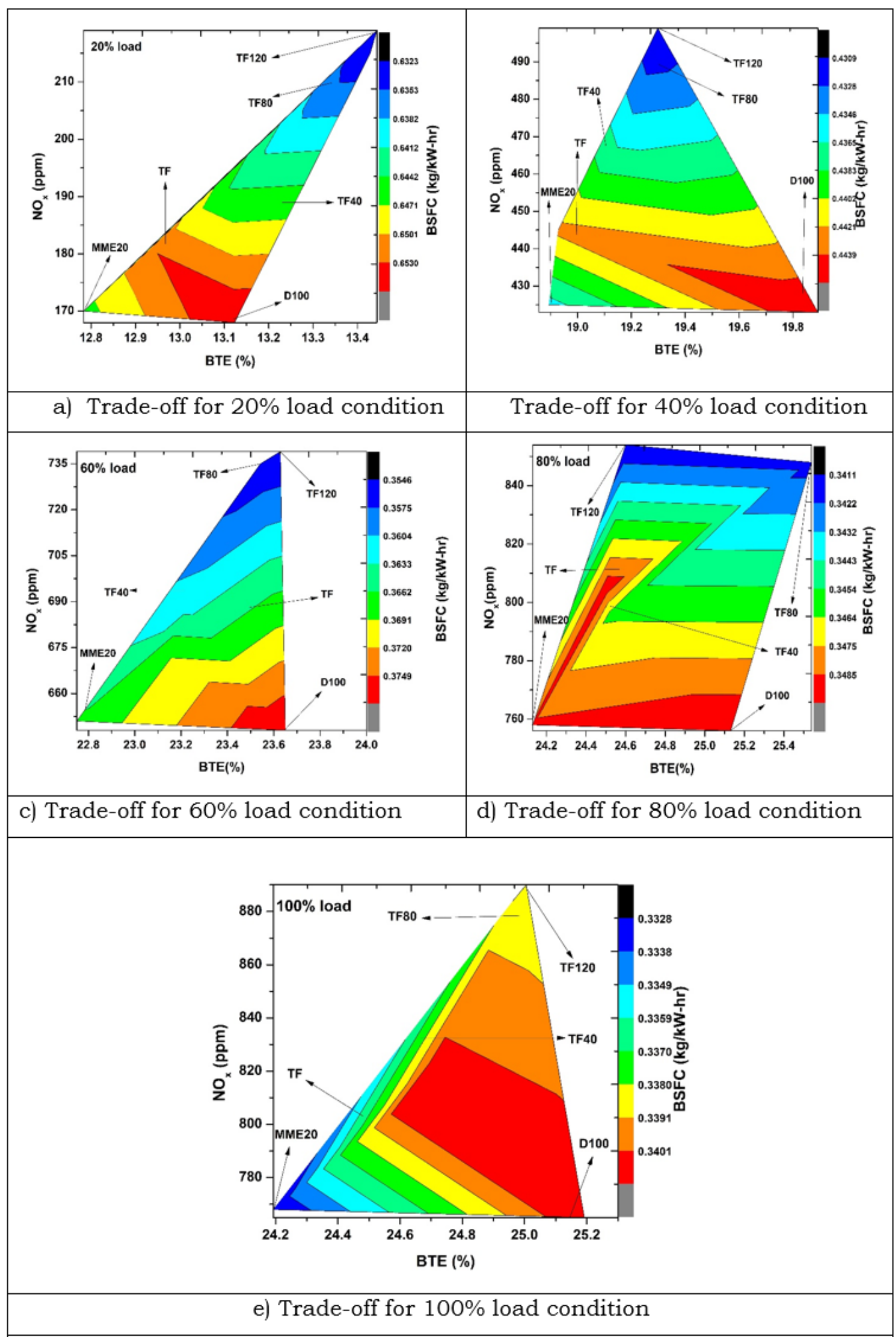

Figure 13

Trade-off study (BSFC-BTE- NOx) 